\title{
The methylome of Biomphalaria glabrata and other mollusks: enduring modification of epigenetic landscape and phenotypic traits by a new DNA methylation inhibitor
}

\author{
Nelia Luviano ${ }^{1}$, Marie Lopez ${ }^{2,3}$, Fleur Gawehns ${ }^{4}$, Cristian Chaparro ${ }^{1}$, Paola B. Arimondo ${ }^{3,5}$, Slavica Ivanovic ${ }^{6}$,
} Patrice David ${ }^{7}$, Koen Verhoeven ${ }^{6}$, Céline Cosseau ${ }^{1}$ and Christoph Grunau ${ }^{1 *}$ (i)

\begin{abstract}
Background: 5-Methylcytosine $(5 \mathrm{mC})$ is an important epigenetic mark in eukaryotes. Little information about its role exists for invertebrates. To investigate the contribution of $5 \mathrm{mC}$ to phenotypic variation in invertebrates, alteration of methylation patterns needs to be produced. Here, we apply new non-nucleoside DNA methyltransferase inhibitors (DNMTi) to introduce aleatory changes into the methylome of mollusk species.

Results: Flavanone inhibitor Flv1 was efficient in reducing $5 \mathrm{mC}$ in the freshwater snails Biomphalaria glabrata and Physa acuta, and to a lesser degree, probably due to lower stability in sea water, in the oyster Crassostrea gigas. Flv1 has no toxic effects and significantly decreased the $5 \mathrm{mC}$ level in the treated B. glabrata and in its offspring. Drug treatment triggers significant variation in the shell height in both generations. A reduced representation bisulfite-sequencing method called epiGBS corroborates hypomethylation effect of Flv1 in both B. glabrata generations and identifies seven Differential Methylated Regions (DMR) out of 32 found both in Flv1-exposed snails and its progeny, from which 5 were hypomethylated, demonstrating a multigenerational effect. By targeted bisulfite sequencing, we confirmed hypomethylation in a locus and show that it is associated with reduced gene expression.
\end{abstract}

Conclusions: Flv1 is a new and efficient DNMTi that can be used to induce transient and heritable modifications of the epigenetic landscape and phenotypic traits in mollusks, a phylum of the invertebrates in which epigenetics is understudied.

Keywords: DNMT inhibitors, 5-Methylcytosine, Mollusks, Invertebrates, Epigenetic inheritance, Epimutation

\section{Background}

DNA methylation is an epigenetic mark that can be associated with changes in gene function without changes in the underlying DNA sequence [29]. Modifications in DNA methylation can be induced by the environment and some changes can be mitotically and/or meiotically

\footnotetext{
*Correspondence: christoph.grunau@univ-perp.fr

${ }^{1}$ IHPE, Univ Perpignan Via Domitia, CNRC, Ifremer, Univ Montpellier, Perpignan, France

Full list of author information is available at the end of the article
}

heritable and/or are reversible [22, 63]. Some of these modifications can influence gene function by providing differential access to the underlying genetic information in cells, and thus may alter their phenotypes. Epigenetic marks, such as DNA methylation, may provide an additional dimension to inheritance, linked to, but different from genetic inheritance. Epimutations can be provoked directly by environmental stresses and contribute to rapid evolutionary changes, but unlike genetic variation, epimutations have higher rates and are reversible $[9,17]$. Biochemically, DNA methylation is the modification of a original author(s) and the source, provide a link to the Creative Commons licence, and indicate if changes were made. The images or other third party material in this article are included in the article's Creative Commons licence, unless indicated otherwise in a credit line to the material. If material is not included in the article's Creative Commons licence and your intended use is not permitted by statutory regulation or exceeds the permitted use, you will need to obtain permission directly from the copyright holder. To view a copy of this licence, visit http://creativecommons.org/licenses/by/4.0/. The Creative Commons Public Domain Dedication waiver (http://creativeco mmons.org/publicdomain/zero/1.0/) applies to the data made available in this article, unless otherwise stated in a credit line to the data. 
DNA base, and is present in a diverse range of eukaryotic organisms, ranging from fungi to mammals [15]. One type of DNA methylation is cytosine methylation that is catalyzed by the DNA methyltransferases (DNMTs), enzymes that transfer the methyl group $\left(-\mathrm{CH}_{3}\right)$ from the co-substrate $S$-adenosyl-L-methionine (AdoMet) to carbon- 5 of cytidines, to form 5 -methylcytidine $(5 \mathrm{mC})$ [61]. In vertebrates, DNA methylation occurs mostly on cytosines in a CpG context except for the CpG islands [84], whereas DNA methylation can also occur in $\mathrm{CHH}$ and CHG $(\mathrm{H}=\mathrm{A}, \mathrm{T}, \mathrm{C})$ context in plants [51]. Less is known about the methylation in invertebrates, though many species present DNA methylation in a CpG context [34].

DNA methylation is assumed to be evolutionary ancient, but its functions and patterns are very diversified. This is consistent with the notion of a dynamically evolving mechanism that can adapt to perform various functions [89] but having a common origin and being always part of an inheritance system [3]. Major differences in DNA methylation are observed among phyla [48]. In the animal kingdom, vertebrates have one of the highest levels of DNA methylation that is uniformly spread all over the genome and found in all sorts of genomic contexts such as gene bodies, gene promoters, intergenic regions, and repetitive DNA such as transposons [75] ("global methylation"). Only promoter sequences are generally unmethylated and methylation here has been demonstrated to modulate gene expression in cis. Methylation also affects DNA repair stability, splicing, imprinting, development, germ cell pluripotency and cell fate [72]. In contrast, in many invertebrates, a common type of DNA methylation is the "mosaic" pattern consisting in large domains of methylated DNA separated by large domains of unmethylated DNA [40]. Another pattern is a very low level [36] or a total absence of DNA methylation [3, 11]. When methylation is of mosaic type, $5 \mathrm{mC}$ is often found in genes (in exons and sometimes to a lesser degree in introns), a type of methylation also called Gene Body Methylation (GBM). GBM is considered as the ancestral form of DNA methylation [25]. Higher GBM is believed to be associated with active transcription in vertebrates and invertebrates, while promoter methylation in vertebrates is associated with repression of gene expression [71].

An important aspect of epigenetic marks is their inheritance. There is evidence in model species, mainly plants [44], that heritable variation in ecologically important traits can be generated through changes in DNA methylation and that these changes may be transmitted to future generations. Nevertheless, in contrast to plants and vertebrates, there is little evidence of transgenerational stability of DNA methylation in other clades such as
Lophotrochozoa, that includes annelids, mollusks, bryozoans, brachiopods and platyhelminthes. Consequently, more evidence is needed about whether environmentalbased DNA methylation changes can be inherited across generations in Lophotrochozoa and in here, we focused on this question in mollusks. DNA methylation has been relatively little investigated in mollusks as discussed in [24], where information is essentially based on data from two species: the pacific oyster Crassostrea gigas and the freshwater snail Biomphalaria glabrata. In the abovementioned work, the authors distinguish the terms multigenerational and transgenerational. Multigenerational effect results from a direct exposure of the germline, gametes, or embryos to the environmental stress, while a transgenerational effect involves a germ line transmission between generations without direct exposure of the germ cells to the environmental stress [24]. In this work, we investigated these two mollusks' species and added the previously unstudied Physa acuta, i.e., three molluscan models of medical, economic, and ecological importance.

The snail B. glabrata is the intermediate host of Schistosoma mansoni, the causative agent of schistosomiasis, a parasitic disease affecting 200 million people in 78 countries [58]. The interaction of these species is characterized by a phenomenon called compatibility polymorphism, meaning that some snail phenotypes can be infected by a specific parasite phenotype while others cannot [78]. It has been demonstrated that epigenetic alterations are involved in the $B$. glabrata parasite compatibility phenotype [49], even though contrasting results have been obtained by others [4, 74]. It remains, therefore, an open question whether epigenetic mechanisms play a role in the capacity of $B$. glabrata to produce phenotypic plasticity or variability. DNA methylation machinery components in B. glabrata include a maintenance DNMT (BgDNMT1), a DNA/tRNA methyltransferase (BgDNMT2) and a methyl-CpG-binding domain protein (BgMBD2/3), BgDNMT1 and BgDNMT2 being probably responsible for the $5 \mathrm{mC}$ modifications $[27,32]$.

Crassostrea gigas is a mollusk of commercial importance and its phylogenetic position and life traits make this bivalve an ideal model to study the physiological, ecological, and evolutionary implications of DNA methylation [68]. In silico analysis revealed that genes predicted to be hypermethylated are generally involved in DNA and RNA metabolism and genes predicted to be sparsely methylated are involved in cell adhesion [69]. Similar results were found in B. glabrata: genes predicted to be methylated are associated with housekeeping functions and genes predicted to be poorly methylated are associated with inducible functions [27]. These findings suggest that DNA methylation has regulatory functions in genes implicated in stress and environmental 
responses meaning it could contribute to increase phenotypic plasticity in mollusks and/or produce potentially heritable phenotypic variation [69].

Physa acuta is one of the most widespread freshwater snail invaders [83] and is an occasional host of several human trematode diseases, including echinostomiasis and fascioliasis [21, 47]. Besides, it has been demonstrated to be a bioindicator species for its sensitivity to environmental contaminants $[7,62]$. P. acuta has a short generation time that makes it a good model for multigenerational studies [73]. Studies about the impact of toxic compounds in the global DNA methylation of $P$. acuta and in its phenotypic traits [7] suggest that DNA methylation can play a role in the phenotypic plasticity of this snail; however, further work is needed to explore this hypothesis.

We borrowed an approach from cancer biology in which the use of DNMT inhibitors (DNMTi) has brought considerable advancements in the understanding of DNA methylation mechanisms but also in therapeutic approaches $[35,54,64]$. The most used DNMTi in many species is 5-azacytidine (5-AzaC) [5, 31, 57], nevertheless important advancements in the design of DNMTi have been done in the last years, notably in decreasing the toxicity and improving the specificity of these compounds [37, 64]. Further, 5-AzaC induces unstable and major side effects, e.g., it caused malformations and apoptosis in the fetal nervous system when administered into pregnant mice [81]. Therefore, we used the commercially available non-covalent nucleoside inhibitor, zebularine [14] and novel generation of non-nucleoside DNMT inhibitors that do not incorporate into DNA, and therefore, induce minimal side effects [23]. In addition, we evaluate if DNMTi-induced DNA methylation modifications are transmitted to their offspring. For global DNA methylation screening, we developed a simple, low cost, antibody-based method to measure DNA methylation levels over large sample numbers and requiring only small amounts of DNA. Our dot blot method and a commercial ELISA-based kit showed equivalent results. For genome-wide methylation profiling, we used epigenotyping-by-sequencing method (epiGBS) [30, 82] a reduced representation bisulfite-sequencing technique that captures a percentage of the epigenome (1-5\%) and we compared the results with a previous methylation information obtained by Whole-Genome Bisulfite Sequencing (WGBS) [1].

We tested two types of DNMTi with different mechanisms of action (Additional file 1: Figure S1). We used zebularine, a nucleoside analogue of cytidine that has proven to be an inhibitor of DNA methylation in human cancer cells [16] but differently from 5-AzaC, it does not form an irreversible covalent complex with the DNMTs
[14] and two custom-made compounds (nitroflavanones) that showed in vitro inhibition activity against DNMT1 and DNMT3A-c in human cancer cell lines [65].

In summary, our results showed that flavanone Flv1 decreased $5 \mathrm{mC}$ level in the exposed generation and mostly in its progeny, it triggered variation in the morphometric traits in both generations and it did not show toxic effects. EpiGBS sequencing confirmed the genomewide effect caused by Flv1 and allowed us to find Differential Methylated Regions (DMRs) between treatment and control samples. Furthermore, a parental effect was demonstrated by the presence of seven Differential Methylated Regions in Flv1-exposed snails and its offspring. Flv1-induced hypomethylation in the BGLTMP010125 locus was associated with reduced gene expression. Since Flv1 inhibitor demonstrated efficiency as DNMTi in $B$. glabrata, it was also tested in the two other mollusk species: the oyster C. gigas and the freshwater snail P. acuta, where it triggered also significant decrease of $5 \mathrm{mC}$, suggesting that Flv1 can be used to modify methylation in other mollusk species.

\section{Results \\ DNMTi Flv1 and Flv2 are suitable for pulse treatment in freshwater}

To induce changes in DNA methylation that were sufficiently strong to lead to phenotypic changes but not strong enough to have toxic effects, we intended to apply a brief DNMTi pulse of only a couple of hours. We, therefore, checked the stability of our new DNMTi in the water environment. The two active flavanones (Flv1 and Flv2) are moderately stable in the enzymatic buffer at $\mathrm{pH}$ 7.2 (EB), there was $12 \%$ of remaining compound after $2 \mathrm{~h}$ for the Flv 1 and $6 \%$ of remaining compound after $4 \mathrm{~h}$ for the Flv2 (Fig. 1). Their stability decreased in freshwater at $\mathrm{pH} 7.8(\mathrm{FW})$, with $29 \%$ of remaining compound after $1 \mathrm{~h}$ for Flv 1 and $45 \%$ of remaining compound after $1 \mathrm{~h}$ for Flv2 (Fig. 1).

The lowest stabilities were found in sea salt water at $\mathrm{pH}$ 8 (SSW), $11 \%$ of remaining compound after $1 \mathrm{~h}$ for Flv1 and $18 \%$ of remaining compound after $1 \mathrm{~h}$ for Flv2. Interestingly, the negative flavanone compound (Flv-neg) was highly stable in the three conditions (EB, FW and SSW) (Fig. 1). Simply the addition of Flv1 and Flv2 to water environment can thus generate a precise pulse of inhibition of DNA methylation activity of $1-2 \mathrm{~h}$ without the need for replacing the water, avoiding confounding stress to the experimental setup.

\section{Flv1 blocks methyltransferase activity on Bge nuclear extracts}

Previous work had shown that Flv1 inhibits directly the DNMT activity in vertebrate cells [65]. We wished to 


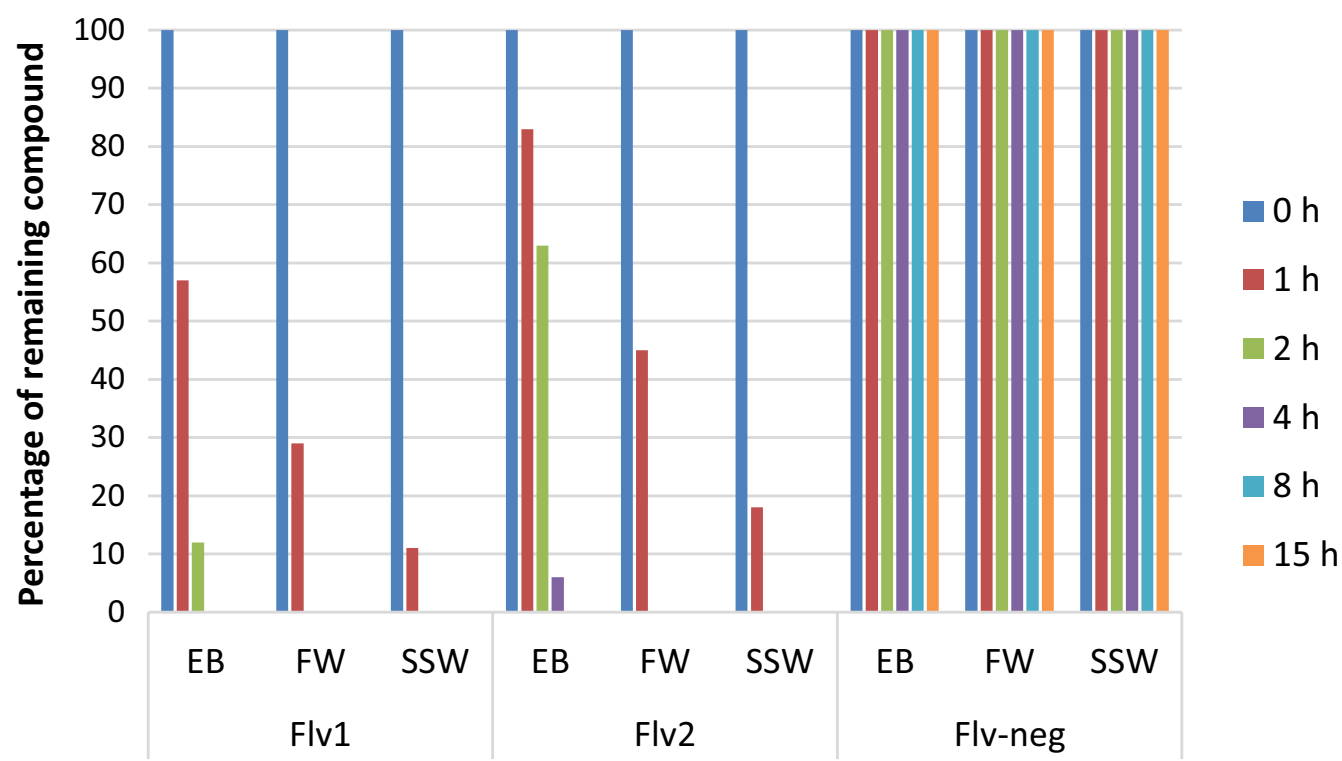

Fig. 1 Flavanone chemical stability in three different media, enzymatic buffer (EB), freshwater (FW) and sea salt water (SSW). Stability was measured by HPLC at $100 \mu \mathrm{M}$ of each compound in the three media

establish such direct action on the methyltransferases in B. glabrata. To do so, we extracted soluble nuclear proteins from $B g e$ cells and performed an in vitro enzyme inhibition assay. We showed that methylation activity of the Bge nuclear protein extract was inhibited by $55 \%$ and $78 \%$ after treatment with $32 \mu \mathrm{M}$ and $100 \mu \mathrm{M}$ of Flv1, respectively (Fig. 2).

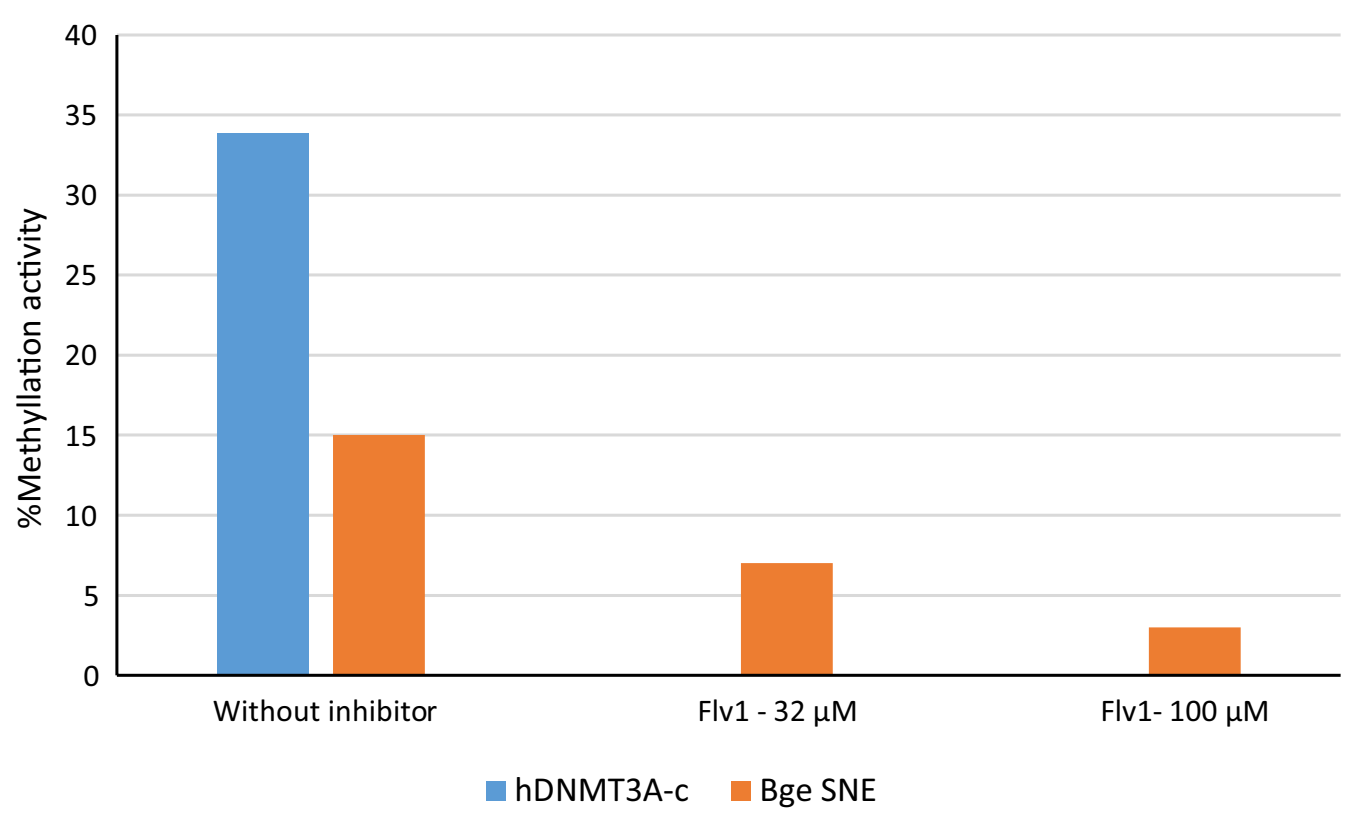

Fig. 2. The level of methylation activity in Bge nuclear protein extract was $15 \%$. After treatment with $32 \mu \mathrm{M}$ and $100 \mu \mathrm{M}$ of Flv1, methylation activity of Bge nuclear protein extract decreased to $7 \%$ and to $3 \%$. Human hDNMT3a-c enzyme was used as a control (blue bar), and its methylation activity was completely inhibited by Flv1 treatment 
Dot blot densitometry allows for cost-efficient screening of $5 \mathrm{mC}$ global level in large sample numbers

In this work, we used a low-cost immunological fluorescence-based method to carry out a large sample screening to measure $5 \mathrm{mC}$ levels in the genome of the mollusk B. glabrata with an antibody against $5 \mathrm{mC}$. A standard curve was generated with different concentrations of DNA from HeLa cells. We found a linear positive correlation between the densitometry measure of each HeLa cell's DNA spots and the $5 \mathrm{mC}$ amount (Fig. 3, $\mathrm{R}^{2}=0.96, p=0.003$ ).

\section{Flv1 decreased DNA methylation in the exposed} generation and dot blot and ELISA-based Kit shows equivalent results

Control and Flv1-treated B. glabrata snails ( $n=15$ per group) were used to measure their $5 \mathrm{mC} \%$ by our dot blot method, and simultaneously, we measured the $5 \mathrm{mC} \%$ with a commercial ELISA-based Kit. We found

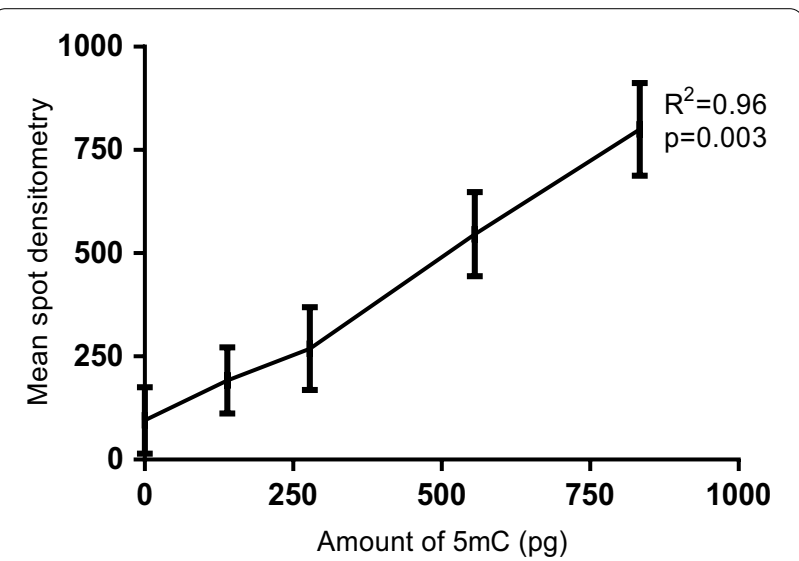

Fig. 3 Linearity of the mean spot densitometry of the HeLa cells obtained from dot blot assay and the amount of $5 \mathrm{mC}$ in pg in each sample. Each ng of HeLa cells contains $4.63 \mathrm{pg}$ of $5 \mathrm{mC}$, five points shown in the graphic correspond to $0,30,60,120$ and 180 ng of HeLa DNA that there was significant difference between control and Flv1-exposed snails in the measures obtained by dot blot assay $(t=5.88, d f=32.70, p=1.389 \mathrm{e}-06)$ and the same was found with ELISA-based commercial kit $(t=3.98$, $d f=34.53, \quad p=0.003273)$. Furthermore, the values obtained after normalization were similar between control samples in both methods, $2.05 \pm 0.74$ and $2.3 \pm 1.4$, respectively, and for Flv1-treated samples, they showed a $5 \mathrm{mC} \%$ of $0.75 \pm 0.47$ with dot blot assay and $0.94 \pm 0.81$ with ELISA-based kit (Fig. 4).

Our results showed that dot blot assay delivered comparable results to established ELISA techniques. Dot blot assay allowed medium high throughput (about 200 samples per day) at low cost (about $3 €$ per sample compared to $19 €$ per sample with ELISA Kit) and required small amounts of DNA (30-100 ng). Furthermore, we found with both methods that Flv1 decreases the global $5 \mathrm{mC} \%$ in the treated snails.

\section{Flv1 influences DNA methylation in vivo in the offspring of treated snails}

Using dot blot method [56], we found significant differences in the $5 \mathrm{mC} \%$ between treatments (Kruskal-Wallis test, $p<0.001)$. In the F0 generation, zebularine did not produce a statistically significant difference in $5 \mathrm{mC} \%$ compared to the control group (Dunn's test $p>0.9$ ). However, $5 \mathrm{mC} \%$ was significantly different in the groups treated with Flv1 $(p<0.001)$ and Flv2 $(\mathrm{p}<0.001)$ compared to control group. The reduction in $5 \mathrm{mC} \%$ between control (2\%) and Flv1 (0.96\%) was twofold (Fig. 5a). Unlike Flv1, Flv2 showed a significant difference compared to inactive flavanone Flv-neg $(p=0.005)$. In F1 generation, offspring snails of the Flv1-exposed generation presented a significantly lower $5 \mathrm{mC} \%(p<0.001)$ than the control group (Fig. 5b). (a). Dot blot assay results

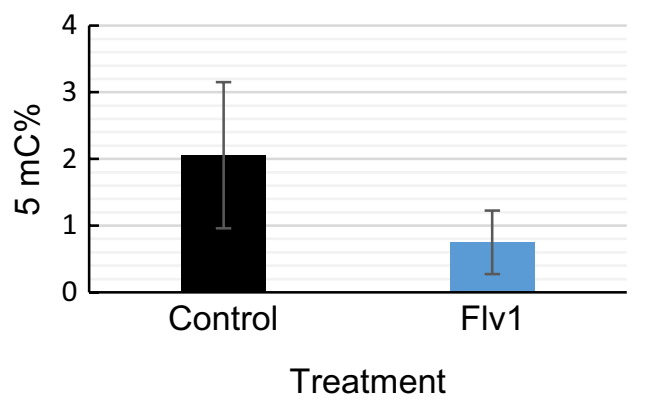

(b). ELISA-based assay results

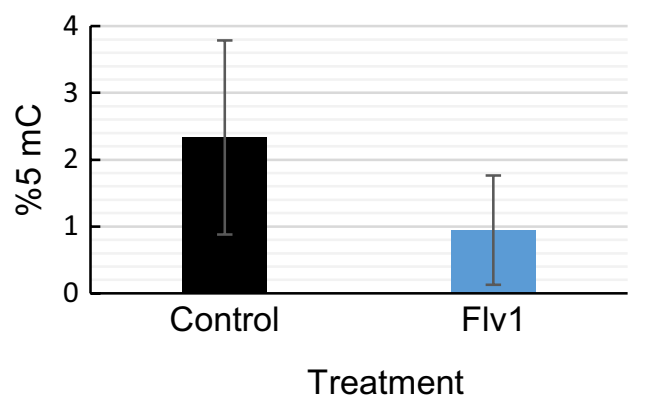

Fig. 4 a $5 \mathrm{mC} \%$ measures obtained by the dot blot method. b $5 \mathrm{mC} \%$ measures obtained by the ELISA-based assay 
(a). Generation F0 (Exposed)

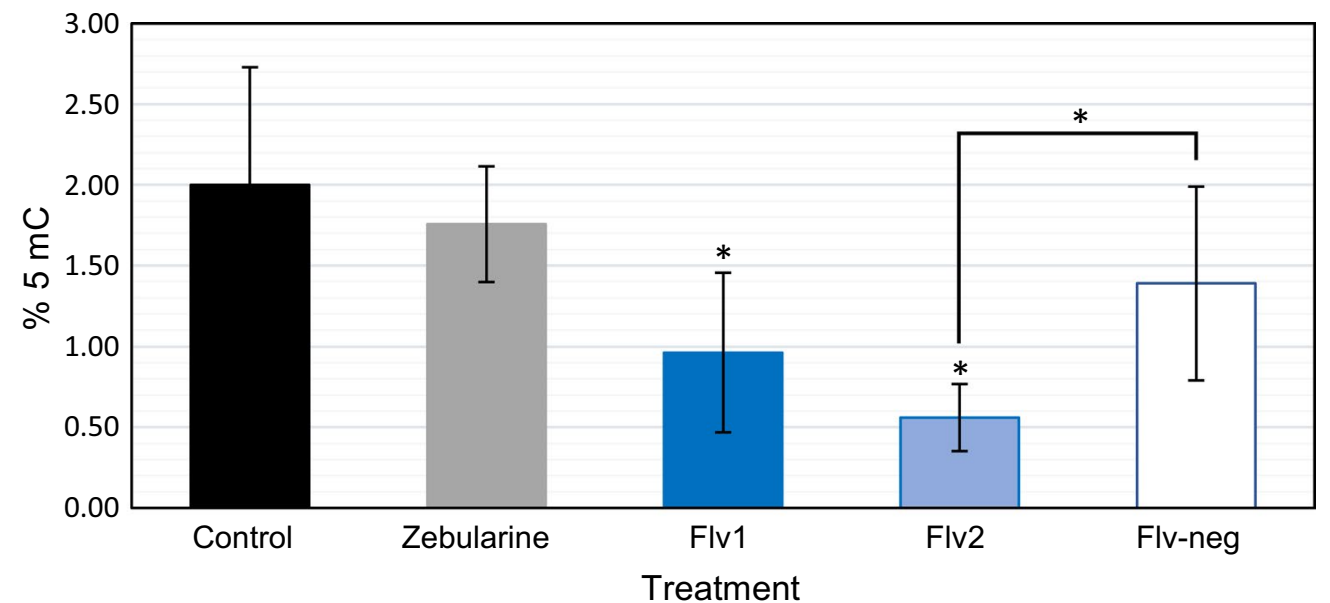

(b). Generation F1 (Not exposed)

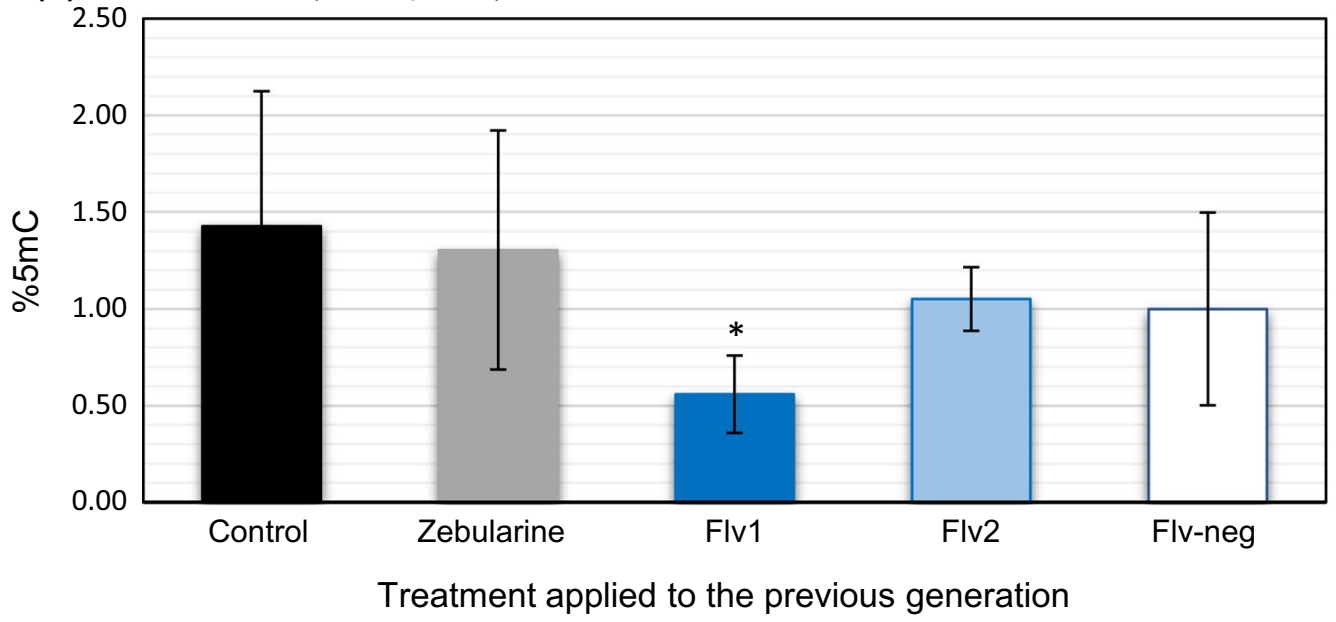

Fig. 5. $5 \mathrm{mC} \%$ of B. glabrata snails upon DNMTi treatments at a concentration of $10 \mu \mathrm{M}$, error bars represent SD, $n=30$ per treatment. a $5 \mathrm{mC} \%$ in the F0 generation (exposed), black bar for control, gray bar for zebularine, blue bars represent flavanone inhibitors (blue bar for Flv1 and light blue bar for Flv2) and the white bar with blue outline represent the inactive Flv-neg. $\mathbf{b} 5 \mathrm{mC} \%$ in the offspring of the exposed snails. Compounds are the ones used in F0. Significant differences are marked as * for $p<0.005 .5 \mathrm{mC}$ ng was normalized to the $5 \mathrm{mC}$ global percentage present in the genome of B. glabrata

\section{DNMTi influence fecundity and morphometric traits}

Since our findings had clearly indicated that Flv1 had an in vivo and in vitro methylating inhibition activity, i.e., probably due to a direct effect on the DNMTs, we wondered if this epimutagenic activity had phenotypic consequences. Therefore, we measured survival, fecundity, and morphometric traits in DNMTi-treated snails and controls. We used as pharmacological reference molecule zebularine. Zebularine induced the lowest mortality with no significant difference compared to control group (Mantel-Cox test $\chi 2=0.3, p=0.56$ ). This compound followed a similar trend as the control and the snail final survival rate reached $80 \%$ compared to $84 \%$ in the control (Fig. 6a). The mollusks treated with Flv1, Flv2 and inactive Flv-neg had a survival rate of $68 \%, 73 \%$, and $69 \%$, respectively (Fig. 6b), and none of these rates were statistically different compared to the control group $\left(\chi^{2}=3.5\right.$, $p=0.06$ for Flv1, $\chi 2=1.16, p=0.2$ for Flv2 and $\chi^{2}=5.9$, $p=0.1$ for Flv-neg).

The fecundity of snails was affected by the treatment with Flv2 and zebularine. Mollusks treated with Flv2 presented a low number of offspring $(n=20)$ and it was significantly different compared to control group $(p=0.004)$. Mollusks treated with zebularine presented 
(a)

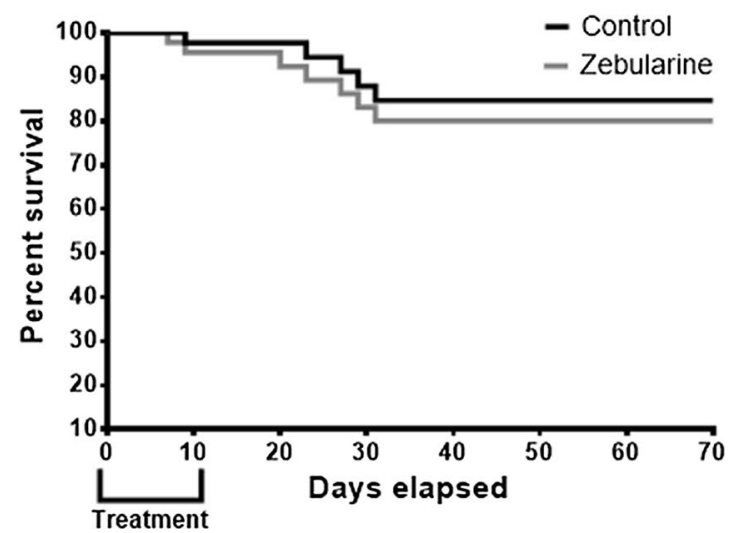

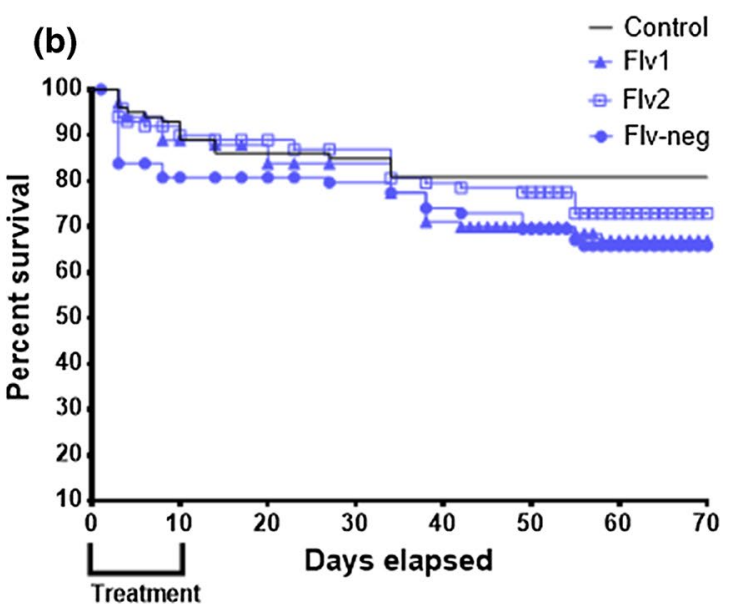

Fig. 6 Kaplan-Meier survival curves upon treatment with the two types of DNMTi. a Cytidine-analogue zebularine (gray line). b Flavanones Flv1 (blue line with triangles) and Flv2 (blue line with squares) and their inactive derivative Flv-neg (blue line with circles)

Table 1 Contingency table of fecundity of the snails exposed to different DNMTi

\begin{tabular}{llllll}
\hline & Control & Flv1 & Flv2 & Flv-neg & Zebularine \\
\hline Total number of laid eggs & 191 & 183 & 199 & 188 & 326 \\
$\begin{array}{l}\text { Number of non-hatched } \\
\text { eggs }\end{array}$ & 152 & 147 & 179 & 147 & 301 \\
Number of offspring & 39 & 36 & $20^{*}$ & 41 & $25^{* *}$ \\
\hline
\end{tabular}

Total number of laid eggs (first row), number of non-hatched eggs (second row) and number of offspring snails (third row). Fisher's exact test was applied, significant differences with control group are marked with * for $p<0.005$ and ** for $p<0.0005$

a significantly lower offspring number than the control group (Fisher's exact test, $p<0.0001$ ) and the number of eggs was very high compared to the other treatments (Table 1). The treatments with Flv1 and Flv-neg showed no significant difference in the number of offspring against control group.

To compare the variation of morphometric traits induced by DNMTi treatment in the F0 generation and in its respective offspring, we performed One-way ANOVA test, Welch's ANOVA or Kruskal-Wallis test per morphometric trait (according to assumptions met). We found significant differences between the treatments of the F0 generation in the shell width $(p=4.001 \mathrm{e}-06)$, the shell height $(p=5 \mathrm{e}-04)$ and mollusk's weight $(p=6.046 \mathrm{e}-$ 07 ), and multiple pairwise comparison between treatments indicated that the difference between control and Flv1 treatment was significant for shell width $(p=0.00018)$, shell height $(p=0.0001286)$ and mollusk's weight $(p=6.0 \mathrm{e}-05)$. In F1 generation, we found significant differences in shell height $(p=1.37 \mathrm{e}-13)$ and mollusk's weight $(p=0.00277)$ between treatments, and multiple pairwise-comparisons, indicated that the difference between the offspring of the snails treated to Flv1 were significantly different to the offspring of controls for the shell height $(p=7.8 \mathrm{e}-05)$. Significant pairwise differences in the shell height were also observed between the offspring of controls and the offspring of snails treated to zebularine $(p=1.0 \mathrm{e}-05)$. Pairwise differences between flavanone compound were found for the mollusk's weight in F1 generation, Flv2 was significantly different to Flv1 and Flv-neg $(p=0.006$ and $p=0.01$, respectively). To visualize the variation of distributions between treatments we performed violin plots (Fig. 7).

\section{Reduced representation of bisulfite-sequencing epiGBS reduces sequencing effort roughly $10 x$ and allows for reliable evaluation of global $5 \mathrm{mC}$ level and identification of differentially methylated sites and regions}

To obtain a clearer picture of where hypomethylation occurred in the epigenomes of the DNMTi exposed populations and their offspring, we adapted a reduced representation technique that was originally developed for mosaic methylation of plants: epigenotyping by sequencing (epiGBS). Since it was only the second time epiGBS was used on mollusks, we first had to make sure that it delivered reliable results here. We used our previously obtained WGBS data [1] to compare the WGBS to epiGBS results on B. glabrata. We reanalyzed the WGBS data with updated pipeline analysis and generated a new reference methylome of $B$. glabrata. Using the BSMAP Mapper, $46.2 \%$ of reads mapped unambiguously to the $B$. glabrata reference genome. Paired-end sequencing of the 32 pooled epiGBS libraries (8 per treatment) resulted in a total of 140,751,495 filtered and demultiplexed reads. After quality control and alignment, an average of $34 \%$ of 


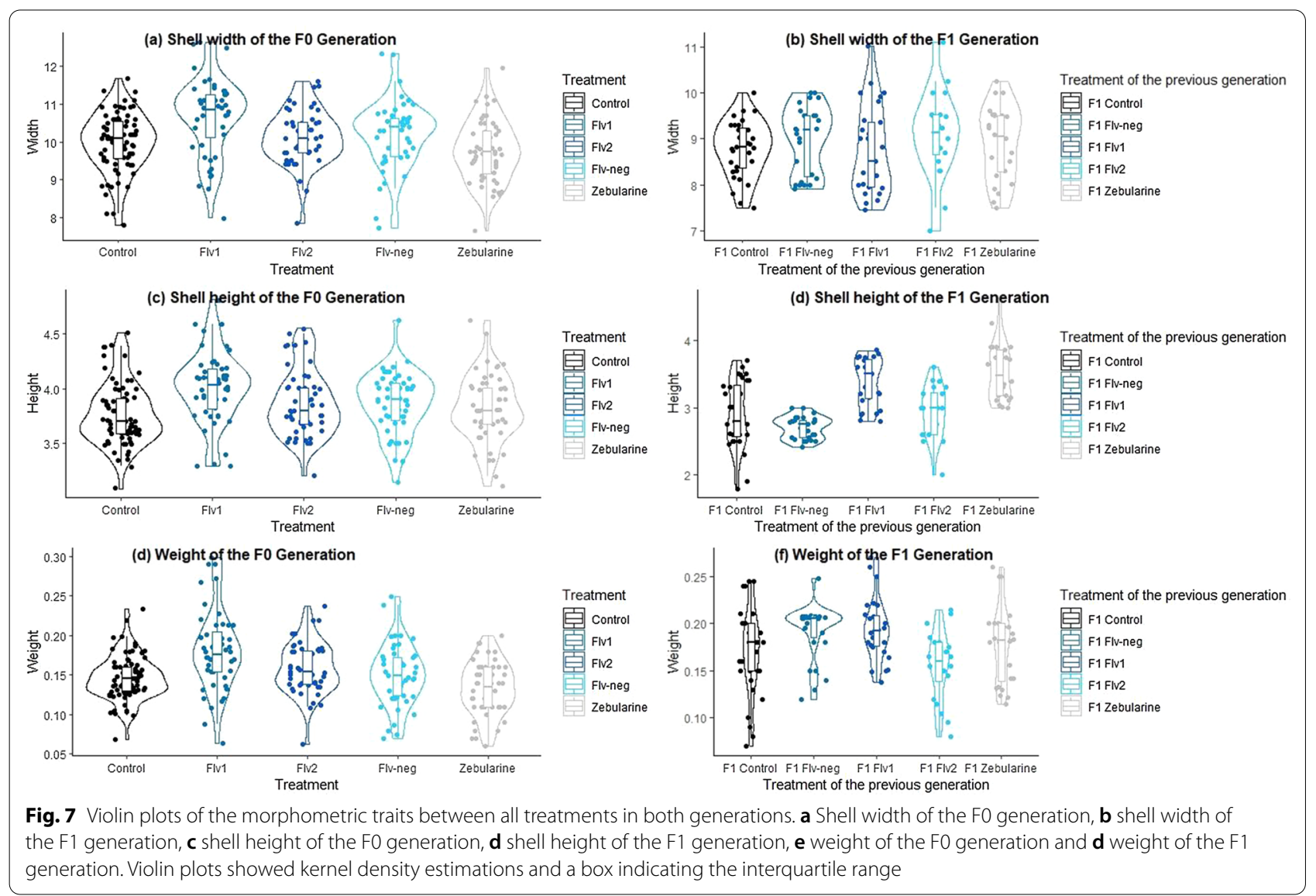

unique reads per sample mapped to the B. glabrata reference genome using BSMAP Mapper (Additional file 1: Table S1). After methylation calling, 6 samples per treatment with $\mathrm{CpG}$ sites covered by $\geq 8$ reads were retained for further analysis, the removed samples showed very low number of $\mathrm{CPG}$ sites $(<4200)$. After filtering, we obtained an average of 47,715 $\pm 31,774$ methylated CpG methylation positions per sample (Additional file 1: Table S1).

To analyze the distribution of methylated $\mathrm{CpG}$ over the entire genome, we represented its frequency distribution. We found a characteristic distribution of two peaks for both WGBS and epiGBS indicating the majority of the CpG sites being either unmethylated or completely methylated, as expected for a species that displays a mosaic distribution type of DNA methylation pattern (Fig. 8a-c). The peak of methylated CpG sites was higher in the epiGBS-sequencing results compared to WGBS, but mean CpG methylation values and confidence interval (CI) of $95 \%$ were highly similar in both methods (Fig. $8 \mathrm{a}-\mathrm{C}$ ).

A direct comparison was done to examine the data obtained for CpG methylation from epiGBS library versus WGBS (Additional file 1: Table S1). We chose the best covered control samples from each generation of epiGBS libraries to compare them with WGBS. WGBS data had a higher mapping efficiency than epiGBS (46.2\% compared to $32.8 \%$ ). The number of $\mathrm{CpG}$ sites with a minimum read coverage of $8 \times$ was of 34,646 and 63,892 for epiGBS libraries and 4,061,906 for WGBS. epiGBS represents $0.8 \%$ (epiGBS F0) and 1.6\% (epiGBS F1) of the CpG sites covered by WGBS. However, the average levels of CpG methylation percentage were very similar between both the methods (Table 2).

To evaluate concordance of epiGBS and WGBS, a correlation was done with the methylation values of $\mathrm{CpG}$ positions covered by both methods. A high correlation was found between WGBS and epiGBS, Spearman correlation, $R=0.74, p<2.2 \mathrm{e}^{-16}$. We also visualized the $\mathrm{CpG}$ methylation profile of epiGBS samples compared to WGBS in IGV in a wide-ranging Scaffold. Visual inspection showed that both epiGBS libraries of F0 and F1-controls have similar methylation profiles (Fig. 9 yellow bars) while, naturally, epiGBS results represent a small fraction of the information found with WGBS (Fig. 9, blue bars).

We then produced the CPG methylation metagene profiles across gene bodies from $2 \mathrm{~kb}$ upstream of the transcription start sites (TSS) and $2 \mathrm{~kb}$ downstream of 

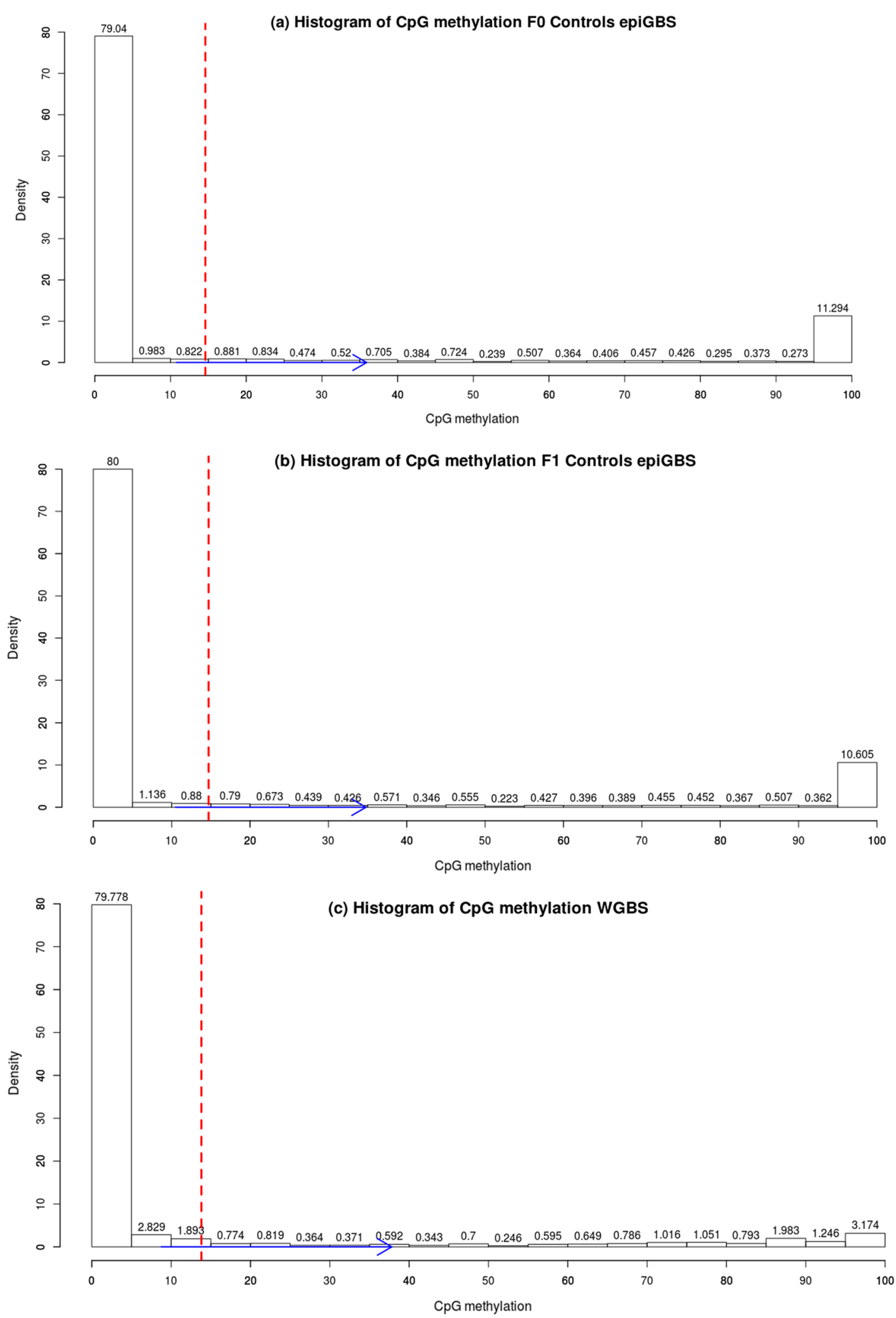

Fig. 8 Histograms of CpG methylation distribution, a histogram of F0-control epiGBS libraries, b histogram of F1-control epiGBS libraries and c histogram of WGBS library. The abscissa represents the CpG methylation \% (0-100) and the ordinate showed the density of CpG positions. The dashed red line indicates the mean CpG methylation value, and the blue arrow indicates the confidence interval (CI) of 95\% 
the transcription end sites (TES). The CpG sites used for these profiles were those covered by both methods (14,340 CpG sites). We found that CpG methylation levels remained a plateau after TSS and along the gene bodies and then showed a high range of methylation before
TSS and after TES in both methods. The range of GBM levels was different in epiGBS libraries (0.9-1) (Fig. 10a, b) than in WGBS (0.7-0.9) (Fig. 10c).

We chose the 14,340 CpG sites within gene bodies (GBM) covered by epiGBS and WGBS libraries to

Table 2 Mapping efficiencies, CpG coverage and average genome-wide methylation levels resulting from epiGBS and WGBS libraries

\begin{tabular}{lllllcc}
\hline Samples & $\begin{array}{l}\text { Mapping } \\
\text { efficiency\% }\end{array}$ & Sequence reads & Total no. CpGs & CpGs $\geq \mathbf{8} \times$ coverage & $\begin{array}{l}\text { Methylated CpG } \\
\text { sites }\end{array}$ & $\begin{array}{l}\text { Methylated } \\
\text { CpG\% }\end{array}$ \\
\hline epiGBS F0 & 34.3 & 707010 & 95369 & 34646 & 7621 & 22.0 \\
epiGBS F1 & 34.5 & 1299293 & 180852 & 63892 & 13982 & 21.9 \\
WGBS & 46.5 & 152842929 & 17493207 & 4061906 & 855624 & 21.1 \\
\hline
\end{tabular}

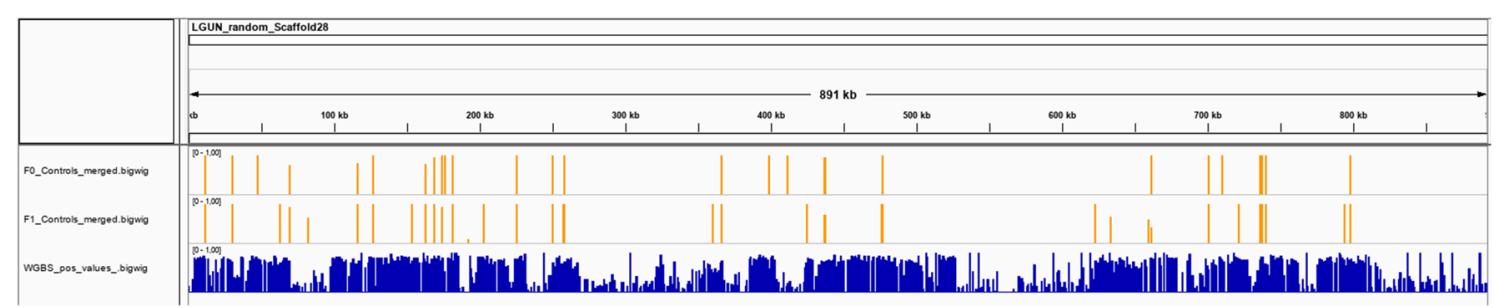

Fig. 9 Screenshot of IGV of the region LGUN_random_Scaffold28: 1-800 Kb, that showed the regions covered by epiGBS libraries (in yellow) versus the regions covered by WGBS library (blue)

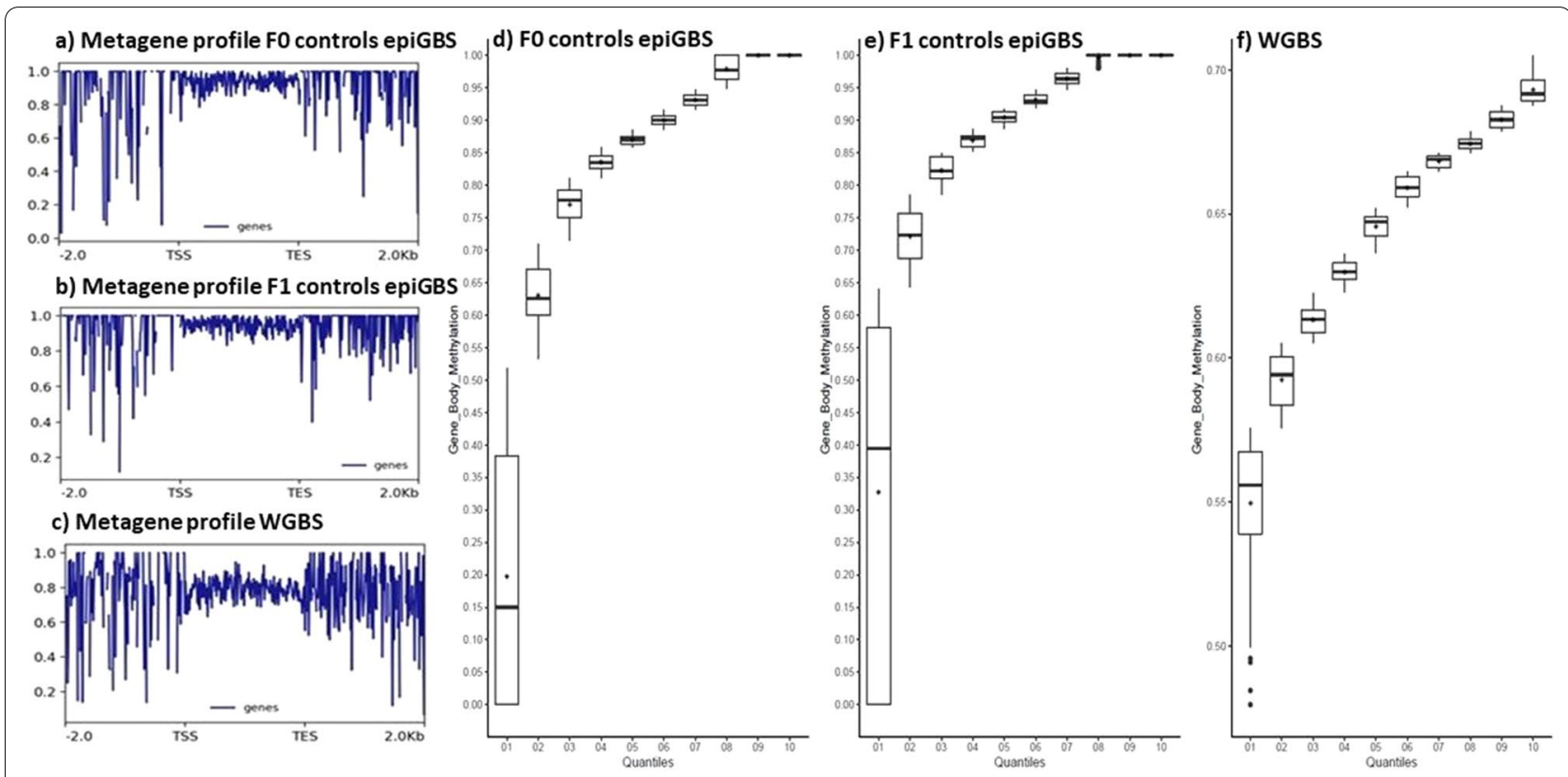

Fig. 10. a Metagene profile of $C p G$ methylation ratio of FO-control epiGBS libraries, Y-axis shows $C p G$ methylation ratio profile across the bodies of genes as average methylation ratio overlapping a $50 \mathrm{bp}$ bin and $\mathrm{x}$-axis $-2.0 \mathrm{~kb}$ indicates the upstream $2000 \mathrm{bp}$ of TSS, and $2.0 \mathrm{~kb}$ indicates the downstream 2000 bp of TES. All gene length arbitrarily scaled to $2 \mathrm{~kb} \mathbf{b}$ metagene profiles of CpG methylation of F1-control epiGBS libraries and $\mathbf{c}$ WGBS library. Quantiles (deciles) distribution of Gene body methylation of $\mathbf{d}$ F0-control epiGBS e F1-control epiGBS and $\mathbf{f}$ WGBS. $\mathbf{d}$-f $\mathrm{Y}$-axis shows CpG methylation ratio profile across the bodies of genes and $x$-axis shows deciles (cut points dividing the range of probability distribution into ten continuous intervals) of epiGBS and WGBS libraries. 
calculate quantile distribution. The quantile distribution of GBM was slightly different between epiGBS and WGBS. In the epiGBS libraries of F0- and F1-controls, the quantile with the highest range is the first one and comprises CpG values of $0.15-0.80$ and $0.47-0.85$ (Fig. 10d, e). Otherwise, in the WGBS library, the first quantile comprises values from 0.07 to 0.58 (Fig. 10f).

The global distribution of CPG methylation sites displayed a two-peak histogram in all epiGBS samples, with most of the CpG sites being either unmethylated or completely methylated. In summary, epiGBS mirrors WGBS on a global scale but has necessarily a lower resolution (at our sequencing depth about $1 \%$ of the CpG sites were captured) and it also has a slight bias towards methylated regions of the epigenome.

\section{epiGBS corroborates hypomethylation in the offspring of snails treated with Flv1 inhibitor}

We considered epiGBS a reliable method that allows for epigenome-wide analysis of DNA methylation changes in populations at reasonable costs and we used it to capture regional methylation differences in Flv1-treated samples. The mean percentage of $\mathrm{CpG}$ methylation was $15.8 \pm 0.8 \%$ in control snails and $13.5 \pm 0.6 \%$ in Flv1exposed snails, $13.5 \pm 0.3 \%$ in offspring of control snails and $13.1 \pm 0.1 \%$ in the offspring of Flv1-exposed snails. There was significant difference in global percentage of CpG methylation between control and Flv1-exposed snails $(t=6.0, d f=9.4, p=0.0001)$ and significant difference was also found in their offspring $(t=3.0, d f=6.0$, $p=0.023)$.

PCA analysis of CpG methylation was performed on controls and Flv1-treated samples (Fig. 11). Interestingly, Flv1-treated samples clustered tightly, while control samples were spread out (Fig. 11a). PCA analysis of CpG methylation in $\mathrm{F} 1$ generation showed the same tendency, F1-Flv1 samples were grouped, and F1-control samples dispersed (Fig. 11b). PCA of both generations displayed the same pattern, indicating an impact in the CpG methylation at the genome-wide level and a decrease of $\mathrm{CpG}$ methylation variability/diversity in both generations.

\section{Five out of 32 Flv1-induced hypomethylated DMRs are present in 2 consecutive generations}

Differential Methylated CpG sites (DMCs) were analyzed between control and Flv1 treatment in both generations. We found 44 DMCs in the F0 generation between control and Flv1-exposed samples, comprising 31 hypomethylated and 13 hypermethylated with the strict methylkit parameters. With the adapted parameters for small sample sizes and weak methylation effects described in [80], we found 245 DMCs, 153 hypomethylated and 92 hypermethylated (Table 3). Interestingly, these DMCs are not isolated and rather concentrated in specific regions (within $1 \mathrm{~Kb}$ ), indicating the presence of differential methylated regions (DMRs). Considering DMR with $\geq 2$ DMCs, the 44 DMCs found with the strict methylkit parameters comprise 10 DMRs and the 245 DMCs found with the adapted methylkit parameters comprise 32 DMRs (Additional file 1: Tables S2, S4).

In F1 generation, 332 DMCs were found between F1-control and F1-Flv1 samples, 207 hypomethylated and 125 hypermethylated (Additional file 1: Table S3) with the strict methylkit parameters, and 1900 DMCs were found between F1-control and F1-Flv1 samples with the adapted methylkit parameters, from which 1153 were hypomethylated and 747 hypermethylated (Additional file 1: Table S5). The majority of hypomethylated DMCs with both parameters demonstrates a hypomethylated genome-wide effect. The number of DMCs in the F1 generation was higher than in the generation F0.

Using adapted methylkit parameters, we found 41 DMCs common between both generations, being 23 hypomethylated and 18 hypermethylated, the hypomethylated DMCs are concentrated in 5 DMRs and the hypermethylated DMCs in 2 DMRs (Additional file 1: Table S7). The context of each DMR found in common between each generation was examined visually in the Integrative Genomics Viewer (IGV) using the B. glabrata genome (Assembly GCA_000457365.1) and the reference transcriptome for annotation. The two hypermethylated DMRs found in common in both generations are in an intergenic context, in the case of hypomethylated DMRs, four are in the intergenic context and one at the putative promoter region of the transcript BGLTMP010125 (Fig. 12).

\section{The BGLTMP010125 gene is hypomethylated by Flv1 and shows decreased transcription}

One of the identified DMR was particularly intriguing. This DMR that was hypomethylated in Flv1-treated snails and in their offspring was close to transcript BGLTMP010125. However, no CpG sites within the BGLTMP010125 were detected by our epiGBS approach so that we could not evaluate gene body methylation (GBM) by this method. We, therefore, decided to apply targeted bisulfite sequencing (TBS). We chose a region in the first intron of the transcript, roughly $2 \mathrm{~kb}$ upstream of the DMR and spanning 9 CpG to further explore the relationship between GBM and gene expression. Our TBS results showed that control snails had five methylated CpG sites in the targeted region of the transcript BGLTMP010125-RA and that the Flv1-treated snails showed a decrease of the $5 \mathrm{mC}$ level in three of the five CpG sites (Table 4), in the CpG 4 of the control snail 6, the decreased of $\mathrm{CpG}$ 
(a) CpG methylation of Control and Flv1-treated snails

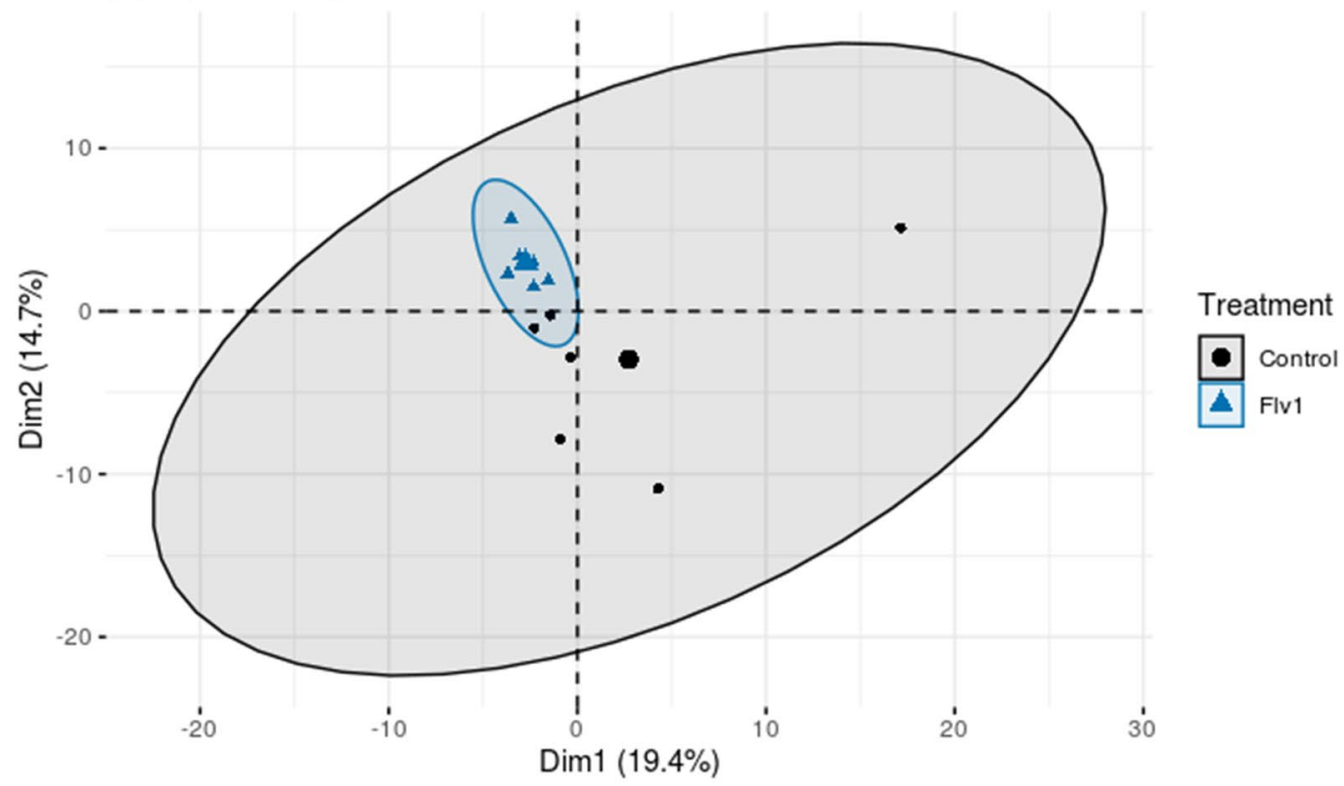

(b) CpG methylation of the offspring of Control and Flv1-treated snails

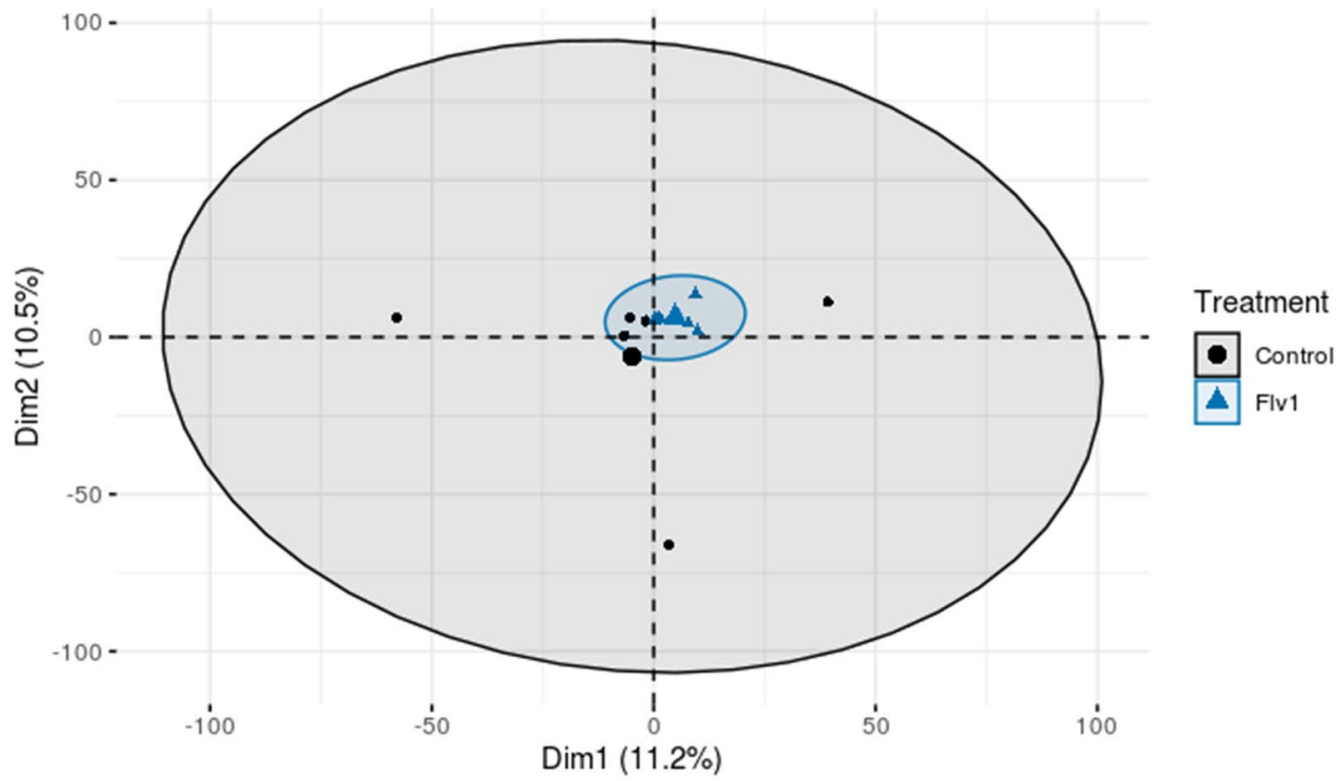

Fig. 11 PCA of CpG methylation of the Flv1-treated and control groups in F0 generation (a) and in its offspring (b). The ellipses represent the 95\% confidence interval

methylation percentage was from 83.2 to $0 \%$. Mean methylation over the 9 CpGs analyzed was significantly lower in Flv1-treated snails $(t=10.58, d f=8.18$, $p=4.673 \mathrm{e}-06$ ) than in controls (Fig. 13a) and the transcript was significantly lower in Flv1-treated samples compared to controls $(t=6.53, d f=10.02$, $p=6.477 \mathrm{e}-05)$ (Fig. 13b).

\section{Flv1 reduces global $5 \mathrm{mC}$ in other mollusks}

Since Flv1 showed efficiency as DNMTi in B. glabrata, and it mostly affected the offspring, we wondered if it would be active also in other mollusk species and we tested Flv1 compound in the juvenile stages of $P$. acuta and C. gigas. The dot blot results (Fig. 14a) displayed that Flv1-exposed $P$. acuta snails have a significantly 
Table 3 DMCs and DMRs in Flv1-treated and control group for each generation

\begin{tabular}{|c|c|c|c|c|c|c|}
\hline Generation & $\begin{array}{l}q \text { value }=0.05 \\
\text { difference }=15 \% \\
\text { DMCs }\end{array}$ & $\begin{array}{l}q \text { value }=1.0, \\
\text { difference }=4 \% \\
\text { DMCs }\end{array}$ & $\begin{array}{l}q \text { value }=0.05 \\
\text { difference }=15 \% \\
\text { Hypomethylated } \\
\text { DMCs }\end{array}$ & $\begin{array}{l}q \text { value }=1.0, \\
\text { difference }=4 \% \\
\text { Hypomethylated } \\
\text { DMCs }\end{array}$ & $\begin{array}{l}q \text { value }=0.05 \\
\text { difference }=15 \% \\
\text { Hypermethylated } \\
\text { DMCs }\end{array}$ & $\begin{array}{l}q \text { value }=1.0, \\
\text { difference }=4 \% \\
\text { Hypermethylated } \\
\text { DMCs }\end{array}$ \\
\hline Fo & 44 & 245 & 31 & 153 & 13 & 92 \\
\hline F1 & 332 & 1900 & 207 & 1153 & 125 & 747 \\
\hline $\mathrm{F} 0$ and $\mathrm{F} 1$ & 6 & 41 & 6 & 23 & 0 & 18 \\
\hline Generation & $\begin{array}{l}q \text { value }=0.05, \text { differ- } \\
\text { ence }=15 \% \\
\text { DMRs }\end{array}$ & $\begin{array}{l}q \text { value }=1 \text {, differ- } \\
\text { ence }=4 \% \\
\text { DMRs }\end{array}$ & $\begin{array}{l}q \text { value }=0.0 .5, \text { dif- } \\
\text { ference }=15 \% \\
\text { Hypomethylated } \\
\text { DMRs }\end{array}$ & $\begin{array}{l}q \text { value }=0.1, \text { differ- } \\
\text { ence }=4 \% \\
\text { Hypomethylated } \\
\text { DMRs }\end{array}$ & $\begin{array}{l}q \text { value }=0.0 .5, \text { differ- } \\
\text { ence }=15 \% \\
\text { Hypermethylated } \\
\text { DMRs }\end{array}$ & $\begin{array}{l}q \text { value }=0.1, \text { dif- } \\
\text { ference }=4 \% \\
\text { Hypermethylated } \\
\text { DMRs }\end{array}$ \\
\hline Fo & 10 & 32 & 6 & 17 & 4 & 15 \\
\hline F1 & 51 & 345 & 38 & 200 & 13 & 145 \\
\hline $\mathrm{F} 0$ and $\mathrm{F} 1$ & 1 & 7 & 1 & 5 & 0 & 2 \\
\hline
\end{tabular}

Two setting parameters were used to calculate the DMCs, the strict parameters with a $q$ value $<0.05$ and a cutoff of $15 \%$ methylation difference and the adapted parameters with a $q$ value $<1$ and a cutoff of $4 \%$

decrease of the $5 \mathrm{mC}(\mathrm{ng})$ concentration compared to controls $(t=5.90, d f=52.23, p=2.76$ e- 07$)$. For $C$. gigas, the decrease in $5 \mathrm{mC}(\mathrm{ng})$ by the Flv1 treatment was also significantly different compared to control $(t=2.18$, $d f=47.946, p=0.0342$ ). The ELISA results (Fig. 14b) showed that the Flv1 compound decreased significantly the $5 \mathrm{mC}$ concentration (ng) in $P$. acuta snails compared to controls $(t=4.80, d f=12.33, p=0.0004)$, and for $C$. gigas, we did not find a significantly decrease of the $5 \mathrm{mC}$ (ng) $(t=1.48, d f=12.11, p=0.16)$ in ELISA-based results but we found a tendency to decrease.

\section{Discussion}

An extension of the concept of inheritance system includes the genotype, the epigenotype, the heritable cytoplasmic elements and the microbiome that interacts with the environment to shape and transmit the phenotype [17]. The epigenotype and the microbiome can be altered by environmental factors and these modifications can be inherited, at least in some systems, through generations, potentially facilitating genetic adaptation. One of the most-studied epigenetic mark is DNA methylation. It has been widely studied in vertebrates and plants but remains poorly understood in invertebrates, one of the largest phyla of invertebrates are mollusks, that include several species that are commercially, ecologically, and medically important. It was hypothesized that DNA methylation in mollusk can be a mechanism to produce phenotypic variation and potentially adaptation to new environments [69], but experimental proof is lacking. DNA methylation in mollusks is likely to be an important element of the inheritance system. One way to analyze its role is to expose the inheritance system to external perturbations that target specifically the DNA methylation, e.g., using DNMTi. Such specific inhibitors were synthetized to be used in human cell lines and they were applied to other phyla assuming they would have the same effect. This strategy already led to important advances in other species where treatments with the most used DNMTi, 5-AzaC, were correlated with demethylation and phenotypic changes [5, 31, 57]. Nevertheless, this drug has shown low response rates, low stability in aqueous solutions and a high toxicity [81]. New DNMTi have been developed to overcome these weaknesses [65]. The aim of this work was to find an efficient DNMTi for mollusks that (i) provoked minimal side effects and (ii) allowed the study of the DNA methylation contribution to phenotypic variability and the heritability of environmental DNA methylation changes.

We used here an antibody-based assay as a screening method of global $5 \mathrm{mC} \%$ modifications. We determined a linear correlation between DNA amount and mean spot density in the dot blot assay, and we demonstrated that it showed comparable results to ELISAbased commercial kit but allowing the screening of a larger number of samples at a lower price (Figs. 3 and 4). Furthermore, we used epiGBS, a reduced representation bisulfite sequencing providing evidence that this method can be used to analyze genome-wide DNA methylation changes. This method allowed the analysis of DNA methylation changes at the nucleotide level of numerous replicates, that is a pre-requisite for ecological studies, at an affordable price and giving results that represent the same global pattern as WGBS, as shown by the high correlation found between the methylation ratios of the $\mathrm{CpG}$ positions covered by both methods (Spearman correlation, $R=0.74, p<2.2 \mathrm{e}^{-16}$ ). We captured only $1 \%$ of the CpG sites found in the genome, however, epiGBS laboratory protocol and bioinformatics analysis are very flexible 


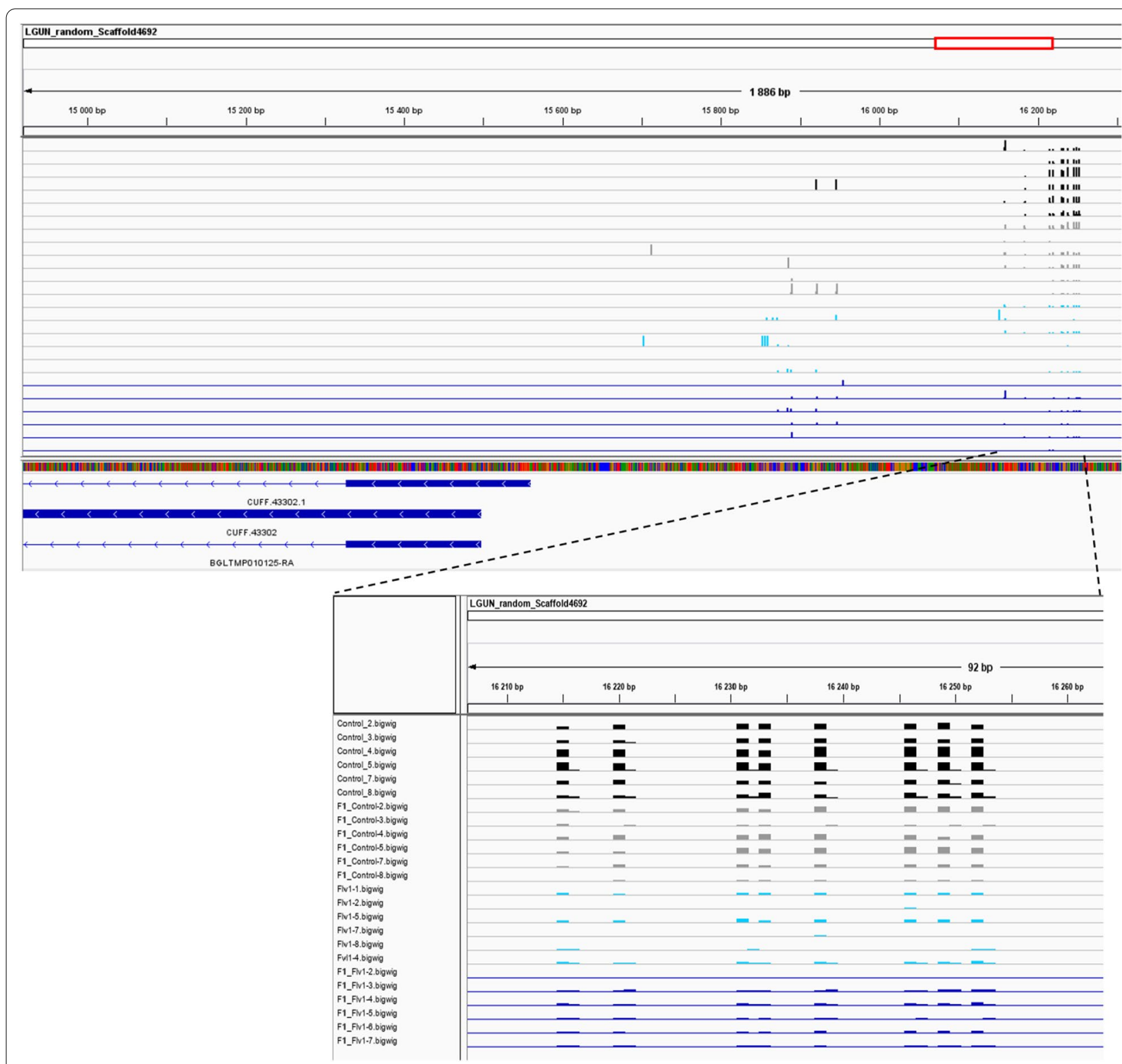

Fig. 12 IGV screenshot of the LGUN_random_scaffold4962:16175-16266 of B. glabrata genome assembly (GCA_000457365.1). Each bar indicates the position of a methylated CpG site for the different samples: F0-control F0 (black), F1-control (gray), Flv1-treated samples (light blue) and its offspring (dark blue). Hypomethylated DMCs have been detected in this region and are in common between F0 and F1 generations

and can be further improved to obtain higher coverage [30].

\section{Zebularine is not suitable for DNA methylation modification in B. glabrata}

Zebularine has been reported as an efficient DNMTi in vertebrates, especially in human cancer cell lines [77]. In this work, we evaluated its effect on the DNA methylation and phenotypic variation on the snail B. glabrata. We decided to use this drug as it is associated with lower cytotoxicity than the nucleoside analogs (5-AzaC and 5-Azadeoxycytidine) due to a different mechanism of action and higher stability in aqueous media $[14,26]$. Nevertheless, the decrease of global DNA methylation was not significant following zebularine treatment. Moreover, we observed an increase in the oviposition of snails treated with Zebularine (Table 2). This phenomenon was also observed in snails exposed to the parasite S. mansoni [79], where oviposition 
Table 4 5mC\% per CpG sites in the bisulfite-converted sequence of the transcript BGLTMP010125

\begin{tabular}{|c|c|c|c|c|c|c|c|c|c|}
\hline CpG sites & CpG 1 & CpG 2 & CpG 3 & CpG 4 & CpG 5 & CpG 6 & $C p G 7$ & CpG 8 & $C p G 9$ \\
\hline $\begin{array}{l}\text { Position on Contig } \\
\text { LGUN_random_Scaffold4692 }\end{array}$ & 13866 & 13976 & 14024 & 14042 & 14059 & 14061 & 14317 & 14331 & 14343 \\
\hline Control 1 & 100 & 0 & 100 & 100 & 0 & 63.4 & 0 & 100 & 0 \\
\hline Control 2 & 88.4 & 0 & 94.2 & 83.3 & 0 & 62.9 & 0 & 95.2 & 0 \\
\hline Control 3 & 100 & 0 & 97.8 & 100 & 0 & 87.8 & 0 & 100 & 0 \\
\hline Control 4 & 100 & 0 & 100 & 100 & 0 & 40 & 0 & 100 & 0 \\
\hline Control 5 & 100 & 0 & 100 & 83.1 & 0 & 73.4 & 0 & 100 & 0 \\
\hline Control 6 & 100 & 0 & 100 & 100 & 0 & 60 & 0 & 100 & 0 \\
\hline Control 7 & 89.5 & 0 & 95.3 & 100 & 0 & 81.1 & 0 & 100 & 0 \\
\hline Control 8 & 100 & 0 & 100 & 83.2 & 0 & 63.0 & 0 & 100 & 0 \\
\hline Flavanone 1 & 0 & 0 & 0 & 0 & 0 & 79.6 & 0 & 76.0 & 0 \\
\hline Flavanone 2 & 0 & & 0 & 0 & & 804 & & 100 & \\
\hline Flavanone 3 & 0 & 0 & 0 & 0 & 0 & 54.3 & 0 & 93.7 & 0 \\
\hline Flavanone 4 & & 0 & & 0 & 0 & 59.4 & 0 & 100 & 0 \\
\hline Flavanone 5 & 0 & 0 & 0 & 0 & 0 & 60 & 0 & 100 & 0 \\
\hline Flavanone 6 & 0 & 0 & 0 & 0 & 0 & 71.9 & 0 & 100 & 0 \\
\hline Flavanone 7 & 0 & 0 & 0 & 0 & 0 & 60 & 0 & 100 & 0 \\
\hline Flavanone 8 & 0 & 0 & 0 & 0 & 0 & 68.4 & 0 & 100 & 0 \\
\hline Control mean & 97.2 & 0 & 98.4 & 93.7 & 0 & 66.4 & 0 & 99.4 & 0 \\
\hline Flavanone mean & 0 & 0 & 0 & 0 & 0 & 66.7 & 0 & 96.2 & 0 \\
\hline
\end{tabular}

(a)
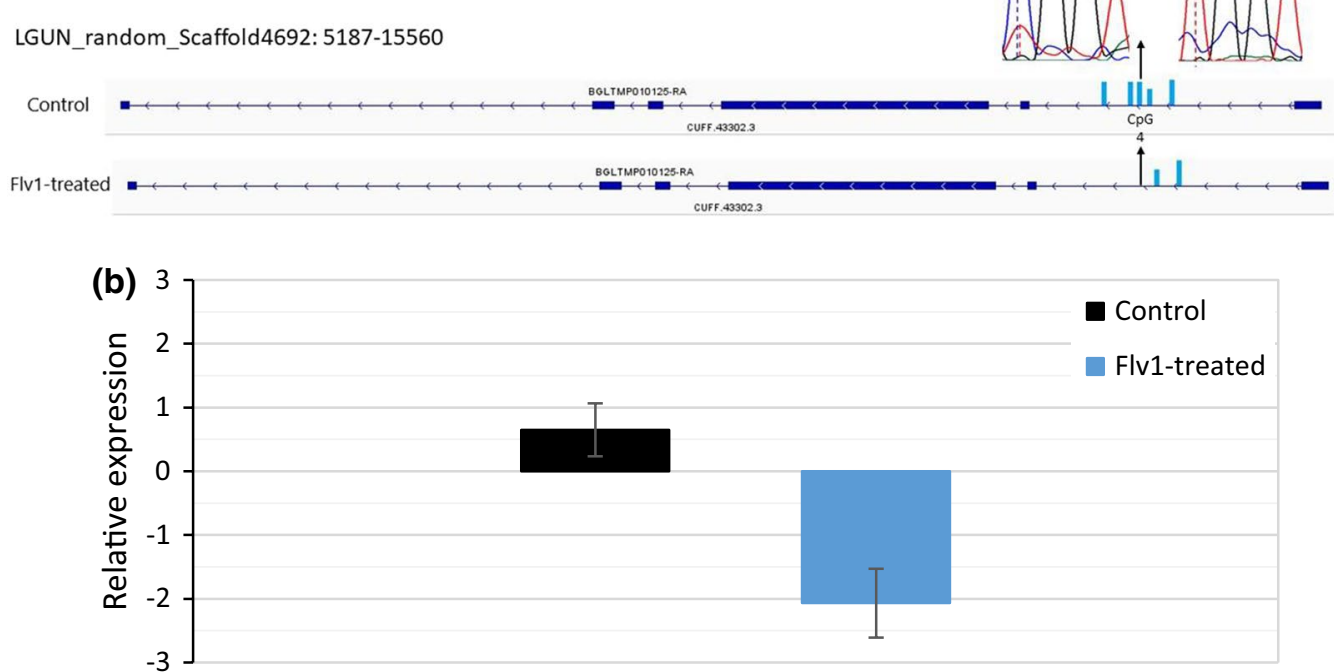

Fig. 13. a Position and level of methylation of the five CpG positions, which has been studied by TBS within the first intron of the transcript BGLTMP010125-RA. b Relative expression of the transcript BGLTMP010125-RA compared to two housekeeping genes (28S and a-Tubulin), the ordinate shows the logarithm of the values obtained with the $2^{-\triangle \Delta C T}$ method 
(a) Dot blot assay results

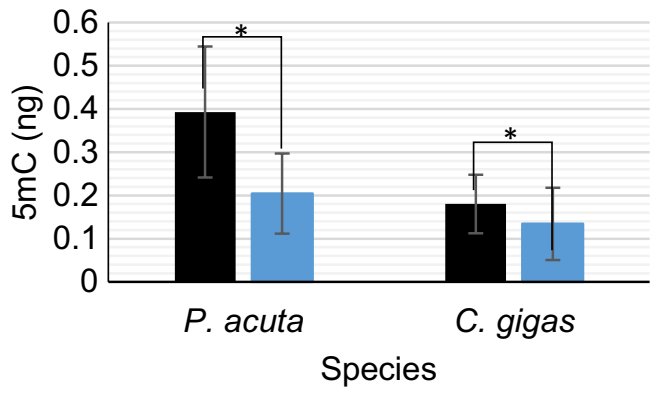

- Control a Flv1-exposed (b) ELISA-based assay results

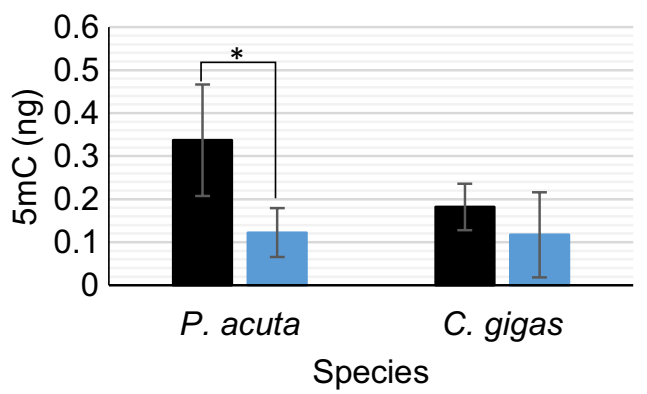

- Control Flv1-exposed

Fig. 14. a $5 \mathrm{mC} \%$ measures obtained by the dot blot method for P. acuta and C. gigas. b $5 \mathrm{mC} \%$ measures obtained by the ELISA-based assay. The bars represent the $5 \mathrm{mC}(\mathrm{ng})$ mean, the error bars represent the standard deviation (SD), $n=30$ per group per specie for dot blot and $n=10$ for ELISA. Significant differences between treatment and control are marked as * for $p<0.05$

is increased during the first days of parasite exposure. This response may be a fecundity compensatory strategy for expected future suppression of egg-laying and it is caused by environmental stress and the toxicity of zebularine possibly triggered this response. Zebularine has demonstrated a transient hypomethylation effect in plants [8], we cannot exclude that the same could happen in B. glabrata, since we observed some phenotypic effects, such as in the fecundity, presenting the lowest percentage of hatching rate in the exposed generation and a significant difference between the shell height of the offspring treated with zebularine and the offspring of the control group, and a tendency to decrease in the global methylation level was also observed. In addition, zebularine is not a specific inhibitor of DNMTs, it also inhibits cytidine deaminase, an important enzyme in the biosynthesis of nucleotides, which can explain the phenotypic effects observed, nevertheless it could be a less efficient DNMTi as most of the compound can be sequestered by this enzyme, and therefore, lowering its effective concentration. This is concordant with other studies showing that, to have an effective inhibition of DNMTs, a high concentration of this compound was required $(\geq 100 \mu \mathrm{M})$ [16].

\section{Flavanone-type inhibitor has no toxic effects and reduces $5 \mathrm{mC}$ level in exposed and offspring of exposed snails}

As a nucleoside analogue, the mechanism of action of zebularine requires its incorporation into DNA after phosphorylation and its conversion to the deoxy-zebularine triphosphate. The new DNMTi tested in this work are non-nucleoside analogues that do not incorporate into DNA being potentially more specific to DNMTs [37]. We tested the Flv1 analogue and showed that Flv1 triggered a significant decrease on $5 \mathrm{mC} \%$ in the F0-exposed generation and in the subsequent non-exposed F1 generation in
B. glabrata. Moreover, we found significant differences in the global methylation level of juvenile mollusks of the species $P$. acuta and $C$. gigas exposed to the Flv1 compound. We further tested the stability of the flavanone compounds (3-halo-3-nitroflavanones) in freshwater and in sea saltwater that was used to raise our mollusks models. We found differences in the chemical stability of Flv1 between freshwater and sea salt water, the compound was $\sim 3$ times more stable in freshwater than it was in sea salt water (Fig. 1), this can explain the results for C. gigas (raised in seawater) where diminution of global DNA methylation was lower than in the freshwater snails P. acuta and B. glabrata. In addition, we demonstrated an in vitro DNMT inhibition activity of the Flv1 compound in a nuclear extract from Bge cells, the embryonic cell line of $B$. glabrata. This suggests that $5 \mathrm{mC}$ modulation triggered by Flv1, was most likely due to direct inhibition of enzymatic DNMT activity.

At the phenotypic level, no significant differences were found in the survival and fecundity between Flv1 and its negative analog (Flv-neg) against the control group. Moreover, Flv1 treatment triggered significant changes compared to controls in the morphometric traits, the snails treated with Flv1 present a significant higher shell width, shell height and mollusks weight against controls; this suggests that the inhibition of DNMT activity by Flv1 led to a significant change in the morphometric traits in the exposed generation. Similar results were found in S. mansoni [18], where we found significant differences in the body length of the parasite larvae between control group and group treated with the epimutagenic TSA, a histone deacetylase inhibitor. Both results showed that modification of epigenetic marks by specific drugs can have effects on the phenotype variability of organisms. Nevertheless, more work is needed to verify if 
epimutations at multiple loci are causing the observed phenotypic variability through post-transcriptional or gene expression changes or if phenotypic variability is independent of these induced epimutations.

The offspring of the mollusks treated with Flv1 were significantly higher in the shell height compared to the offspring of control snails. This suggests that the germline was possibly affected by the Flv1 inhibitor which affected the shell height of their offspring.

Flv2 showed a negative impact in the fecundity of treated snails and a significant decrease of the global $5 \mathrm{mC}$ in the treated snails that was significantly different compared to Flv-neg. Moreover, the offspring of the mollusks treated with Flv2 were significantly lower in their weight compared to the offspring of those treated with Flv1 and Flv-neg. These effects suggest a side effect of this compound that was probably due to its different chemical composition. Flv2 possesses a chlorine atom in the $\alpha$-position of the carbonyl group and Flv1 possesses a bromine atom at the same position, which makes that the two compounds present different DNMT inhibition potency, cytotoxicity, and stability [65]. Flv1 induced a higher gene expression activity in KG1-cells, by decreasing promoter methylation compared to Flv2. Moreover, Flv1 triggered lower cytotoxicity compared to Flv2 in different cancer cell lines [65] and in our results, it showed lower stability in freshwater than Flv2. Therefore, Flv2 was more stable in freshwater but also more toxic against snails which explains its high effect in F0 generations and its subsequent compensatory effect in the next generation in the form of hypermethylation, similar results were found in DNA methylation levels of the TRL 1215 cell line after Cadmium exposure, which inhibits DNA methyltransferases as part of its toxicity and when exposure is prolonged it results in DNA hypermethylation [76]. Flvneg was inactive in an in vitro inhibition assay against purified human DNMT3A-c [65].

We corroborated Flv1 hypomethylation effect in $B$. glabrata by high-throughput bisulfite sequencing with the epiGBS method, confirming that the average of overall percentage of $\mathrm{CpG}$ methylation was significantly lower in Flv1-exposed snails compared to controls and the same trend was found in its offspring. To find differentially methylated cytosines, we decided to analyze our data using two levels of stringency: (1) a strict and most stringent one filtered the DMC based on a $q$ value $<0.05$ and $15 \%$ of methylation difference that has been normally used in other mollusks species and has been defined based on studies of model species [2] and (2) an adapted method filtered the DMC based on a $q$ value $<1$ and $4 \%$ of methylation difference and has previously been applied to small sample sizes and allows to find small differential methylation effects [80]. A total of 44 DMCs were found in the Flv1-exposed snails compared to controls with the strict methylkit parameters and 245 DMCs with the adapted methylkit parameters. Its progeny showed 332 DMCs compared to F1-controls with the strict methylkit parameters and 1900 DMCs with the adapted methylkit parameters. The higher number of DMCs in the F1 generation might be due to an indirect exposure of the germline to the inhibitor. In mollusks, germ cells appear early in the embryonic development [55]. It has been demonstrated that exposure of the germline to DNMTi affects epigenetic programming in sperm and oocytes and are likely to affect outcomes and offspring development principally in vertebrates $[66,85]$.

Seven DMRs were observed in Flv1-exposed snails and in its progeny, five hypomethylated and two hypermethylated, demonstrating a multigenerational effect, resulting probably from a direct exposure of the germline to the inhibitor. Few examples of multigenerational effect have been reported in mollusks [24], one is our previous study in $C$. gigas showing that a parental herbicide exposure strongly affected the offspring DNA methylation pattern [70]. Another example was found in P. acuta, where exposure to prednisolone, a steroid hormone evacuated from hospital wastewater, negatively affected the phenotypic traits of the snail, exhibited multigenerational toxicity, and affected global DNA methylation of adult progeny [7].

One of the hypomethylated DMRs found in both $B$. glabrata generations mapped to the putative promoter region of transcript BGLTMP010125 coding for a thump domain-containing protein 3-like. A protein BLAST (blastp) with the amino acid sequence of this protein showed $66.4 \%$ of identity with the THUMP domaincontaining protein 3-like of Aplysia californica (NCBI reference sequence XP_012941090) and 52.8\% of identity with the THUMP domain protein 3 of the brachiopod Lingula anatina (XP_013378720.1), and these proteins are part of AdoMet_MTases superfamily, enzymes that use $S$-adenosyl-L-methionine (Adomet) as a substrate for methyltransferase, creating the product $S$-adenosyl-L-homocysteine. TBS in the first intron showed that the Flv1 inhibitor treatment decreased significantly the GBM level in this transcript. qPCR indicated reduced gene expression in Flv1-treated F0 generation. Interestingly, the gene impacted by the inhibitor is coding for a AdoMetdependent methyltransferase whose decreased expression could have leverage effects on $5 \mathrm{mC}$ level at multiple loci by influencing AdoMet homeostasis. These results are in agreement with earlier results in the invertebrates Nematostella vectensis and Bombyx mori $[87,88]$, where a positive linear correlation was found between GBM and mRNA levels. 
In conclusion, the compound Flv1 was sufficiently stable in freshwater for $4 \mathrm{~h}$ to trigger cytosine modifications that were transmitted through mitosis in the F0 generation and through meiosis to the F1 generation. Flv1 demonstrated to be a good candidate to perform multigenerational DNMTi experiments: it neither impacts fecundity nor survival and it induces seven DMRs found in two consecutive generations; moreover, it showed higher inhibition potency in the offspring of treated individuals probably due to a direct impact in the germline. Since DNMTs are a conserved family of cytosine methyltransferases and since we showed that Flv1 inhibitor is efficient in another two mollusk species P. acuta and $C$. gigas, we suggest that this new DNMTi could be used to pharmacologically modify $5 \mathrm{mC}$ level in mollusks, providing a tool to study the inheritance of $5 \mathrm{mC}$ environmental modifications in this taxon.

In neo-Darwinian theory, genetic variation is considered a pre-requisite for hereditary phenotypic variation and as the primary material of adaptation by natural selection. Nevertheless, it has been demonstrated that the epigenetic inheritance system allows the environmentally induced phenotypes to be transmitted between generations, which can constitute the basis of adaptative phenotypic plasticity [41, 42]. Moreover, epigenetic changes can be behind rapid adaptive changes observed in scenarios such as climate change, biological invasions and coevolutionary interactions. However, we need to disentangle the epigenetic variation from the genetic one and for that we need approaches that allow us to decrease genetic background (e.g., self-fertilization breeding) and introduce epigenetic changes (e.g., epidrugs, gene knockouts).

Our results hint at epimutations being a source of phenotypic variance that can be induced by chemicals that disrupt normal mechanisms of methylation control. In addition, this disruption may act on the germline, with phenotypic expression in the form of heightened phenotypic and epigenetic variance in the next generation. However, we have no proof that variation in methylation patterns is the only source of the variance in the phenotype found in F0 and F1 generations and we cannot formally exclude concomitant genetic variation. However, Flv1 could be used to induce epimutations in inbred self-fertilization lines and cross snails with divergent methylomes due to chemical treatment (e.g., hypomethylated versus hypermethylated snails) to create epigenetic recombinant inbred lines (epiRILs) as those created in Arabidopsis thaliana [44]. In this way, one can evaluate if, in the absence of genetic variation, epimutations and phenotypic variation induced in the exposed generations are transmitted across multiple generations and produce phenotypes having a selective advantage.

\section{Methods}

\section{Ethics statement}

B. glabrata adult snails of the albino Brazilian strain (BgBRE) were used in this study. P. acuta juvenile individuals were raised in the Centre d'Ecologie Fonctionnelle et Evolutive CEFE UMR 5175 in Montpellier, France. C. gigas juveniles' oysters were a generous gift of Bruno Petton from the Marine Mollusks Platform IFREMER in Bouin, France. B. glabrata mollusks were maintained at the IHPE laboratory facilities; they are kept in aquariums and fed with lettuce ad libitum. C. gigas and $P$. acuta mollusks were maintained during the 10 days of drug exposure in the quarantine room at the IHPE laboratory to avoid contact with the home breeding species (B. glabrata strains). The Direction Départementale de la Cohésion Sociale et de la Protection des Populations (DDSCPP) provided the permit $\mathrm{N}^{\circ} \mathrm{C} 66-136-01$ to IHPE for experiments on animals. Housing, breeding, and animal care were done following the national ethical requirements.

\section{Chemical stability measurement of the new DNMT inhibitors}

The stability of the flavanone compounds Flv1, Flv2 and Flv-neg corresponding to compounds MLo1507 (3b), Flv880 (880) and MLo1607 (19) in [65] was measured by High-Performance Liquid Chromatography (HPLC) by the method described in [65]. HPLC analysis were done using an X-terra column $(100 \times 4.6 \mathrm{~mm}, 5 \mu \mathrm{m})$ with $1 \mathrm{~mL} / \mathrm{min}$ flow and the following gradient: $\mathrm{H}_{2} \mathrm{O}$ acetonitrile 95:5 for 2 min then up to 0:100 in $10 \mathrm{~min}$ and maintained at 0:100 for 2 min with $\mathrm{H}_{2} \mathrm{O}$ and acetonitrile containing $0.1 \%$ of trifluoroacetic acid. First, flavanone compounds (Flv1, Flv2 and Flv-neg) were injected in solution at $100 \mu \mathrm{M}$ in $100 \%$ DMSO to check its purity. Then, $50 \mu \mathrm{L}$ of solution at $10 \mu \mathrm{M}$ of tested compound was prepared by dilution in DNMT3A-c enzyme buffer (Hepes $20 \mathrm{mM}$ pH 7.2, KCl $50 \mathrm{mM}$, EDTA $1 \mathrm{mM}$ final concentration), in freshwater used in the aquariums of $B$. glabrata or in filtered sea water used in the aquariums of C. gigas. The percentages of remaining compound were determined with the area of the corresponding HPLC peak on the $250 \mathrm{~nm}$ chromatogram.

\section{Bge nuclear fraction extraction}

Nuclear fractions were prepared by collecting Bge cells (the embryonic cell line of our model B. glabrata) by centrifugation, then cell pellet was lysed with a dounce homogenizer $(7 \mathrm{~mL})$ for $10 \mathrm{~min}$ at room temperature with cold $10 \mathrm{mM}$ HEPES pH 7.7, $10 \mathrm{mM} \mathrm{KCl,} 0.1 \mathrm{mM}$ EDTA, $1 \mathrm{mM}$ DTT, and 0.4\% IGEPAL CA-630 in the presence of protease inhibitors. The lysed cells were 
centrifuged at $15,000 \times \mathrm{g}$ for $3 \mathrm{~min}$ and the soluble fractions removed. The pellet was resuspended in $20 \mathrm{mM}$ HEPES pH 7.7, 0.4 M NaCl, 10\% glycerol, $1 \mathrm{mM}$ DTT in the presence of protease inhibitors by vortexing for $2 \mathrm{~h}$ at $4{ }^{\circ} \mathrm{C}$, followed by centrifugation at $15,000 \times \mathrm{g}(5 \mathrm{~min}$, $4{ }^{\circ} \mathrm{C}$ ) to provide the nuclear fractions (supernatant) and a membrane pellet. The nuclear fractions were quantified with the 2D Quant Kit (GE Healthcare Life Sciences, USA) and then stored at $-80^{\circ} \mathrm{C}$ until use.

\section{DNMT inhibition methyltransferase activity on Bge nuclear extracts}

Flv 1 inhibition activity was determined on Bge nuclear extracts with a fluorescence-based assay [13]. In brief, a double-strand DNA with a unique CpG site overlaying an endonuclease restriction site for methylation-sensitive enzyme was used. This oligonucleotide comprises a 6-carboxyfluorescein (6-FAM) at one end and biotin on the other end allowing immobilization into a 384well plate (PerkinElmer) pre-coated with avidin. Flv1 and AdoMet as methyl donor were added followed by DNMT3A-c to start the methylation reaction, which was prolonged $1 \mathrm{~h}$ at $37{ }^{\circ} \mathrm{C}$. After several washing, with $\mathrm{PBS}$ tween $(0.05 \%)$ containing $\mathrm{NaCl}(0.5 \mathrm{M})$ and PBS tween (0.05\%). Restriction step was performed with HpyCH4IV (New England, BioLabs) to hand on only the specific fluorescence signal. Fluorescence was quantified on a spectrofluorometer SAFAS FLX-Xenius. Methylation activities are defined as $\left[\left(\mathrm{X}_{\text {meth }}-\mathrm{X}_{\text {restri }}\right) /\right.$ $\left(\mathrm{X}_{\mathrm{DNA}}-\mathrm{X}_{\text {restri }}\right] \times 100$, where $\mathrm{X}_{\text {meth }}, \mathrm{X}_{\text {restri }}$ and $\mathrm{X}_{\mathrm{DNA}}$ are, respectively, the fluorescence signals of the compound methylation, restriction, and DNA controls.

\section{DNA methyltransferase inhibitor (DNMTi) treatments in $B$. glabrata}

Three types of DNMT inhibitors were tested in the snail B. glabrata, the cytidine analogue zebularine (Sigma, France, Cat. No. 3690-10-6) and custom-made inhibitors, previously selected for their inhibitory activity against $h$ DNMT 1 and $h$ DNMT3-c [13], [65].

The custom-made compounds consist in the active flavanones: Flv1, Flv2, and Flv-neg corresponding to compounds MLo1507 (3b), DD880 (880) and MLo1607 (19) in [65]. Stock solutions at $10 \mathrm{mM}$ were made in ultrapure Milli-Q water and aliquoted and stored at $-20{ }^{\circ} \mathrm{C}$ for all compounds.

For each condition, 100 adult snails of the B. glabrata Brazilian strain ( $B g$ BRE) of approximately the same age (8 weeks) and size $(5-7 \mathrm{~mm})$ were randomly assigned to treatment and control groups, the treatments were done with the DNMTi at a final concentration of $10 \mu \mathrm{M}$ in $1000 \mathrm{~mL}$ of well water in a plastic container, a single aquarium was made within each treatment. The $B g$ BRE strain is not an inbred strain, it can show concomitant genetic variability [12]. The water was replaced once with fresh drug-containing water at the same concentration, the replacement was performed after 3 days and $22 \mathrm{~h}$. After 10 days of exposure, the drug was removed and replaced by drug-free water. Snails were then raised in the plastic tank for 70 days, during which different life history traits were measured. Mortality was measured at days 3, 4, 6, 8 and then each week. The egg-capsules laid by the snails of the generation F0 were separated each week to raise the F1 generation in another plastic container, the fecundity was reported as a single measure of number of juveniles and total number of eggs per treatment. At day 70, snails of the generation F0 and F1 were collected, the shell width, shell height and weight of each snail were recorded to compare morphometric trait variations between treatments. Finally, snails were stored wrapped in aluminum sheets individually at $-20^{\circ} \mathrm{C}$.

\section{Flv1 treatment in C. gigas and P. acuta}

Thirty individuals of $P$. acuta and 30 of $C$. gigas of 5-7 mm of diameter were raised as the control groups. Thirty individuals of $P$. acuta and 30 of C. gigas of the same size were exposed to the Flv1 inhibitor at a concentration of $10 \mu \mathrm{M}$. The water was replaced once with fresh water for P. acuta and with filtered sea water for C. gigas both containing Flv1 inhibitor at the same concentration, the replacement was done after 3 days and $22 \mathrm{~h}$. After 10 days of exposure, snails and oysters were collected and stored in aluminum sheets individually at $-20{ }^{\circ} \mathrm{C}$.

\section{Genomic DNA extraction}

Zirconia/Silica beads and the NucleoSpin ${ }^{\circledR}$ Tissue Kit (Macherey-Nagel, Düren, Germany), a method developed to extract DNA from the Pacific oyster [19], were used for DNA extraction from whole body without shell of B. glabrata ( $n=300,30$ per treatment), P. acuta $(n=60)$ and $C$. gigas $(n=60)$. Briefly, for the lysis phase, $180 \mu \mathrm{L}$ of lysis buffer, $25 \mu \mathrm{L}$ of Proteinase $\mathrm{K}(20 \mathrm{mg} / \mathrm{mL})$ and $100 \mu \mathrm{g}$ of zirconia/silica beads (BioSpec, USA, Cat. No. $11079110 \mathrm{z}$ ) were added to samples that were submerged in liquid nitrogen and then shaken in a Mixer Mill (Retsch MM400) at a frequency of $30 \mathrm{~Hz}$ for $12 \mathrm{~min}$. Then, an incubation in water bath at $56{ }^{\circ} \mathrm{C}$ during $1 \mathrm{~h} 30$ was done.

After lysis, the NucleoSpin ${ }^{\circledR}$ Tissue Kit protocol was applied according to the manufacturer instructions. Elution was performed into a final volume of $100 \mu \mathrm{L}$ elution buffer. The samples were stored at $-20{ }^{\circ} \mathrm{C}$. DNA concentrations of all samples were quantified using a Qubit ${ }^{\circledR}$ 
2.0 fluorometer (Invitrogen) and a fluorescence-based Qubit $^{\mathrm{TM}}$ dsDNA BR Assay Kit (Invitrogen, Q32853).

\section{Global DNA methylation detection Dot blot}

Detection and quantification of DNA methylation in genomic DNA were performed by dot blot assays using an antibody against $5 \mathrm{mC}$. Before large screening, we optimized the dot blot method with DNA extracted from HeLa cells as a positive control and unmethylated PCR products as negative control. Different concentrations of HeLa cells were spotted to test the sensitivity and linearity of the method. After standardization of the method, genomic DNA of the control and treated mollusks (100 ng in $5 \mu \mathrm{L}$ per replicate for equal loading) were denatured with $0.3 \mathrm{M} \mathrm{NaOH}$ at $42{ }^{\circ} \mathrm{C}$ for $10 \mathrm{~min}$ and spotted on nitrocellulose membranes $\left(\right.$ Hybond $^{\circledR}$ ). The membranes were blocked in 5\% powdered milk diluted in $1 \times$ TBS containing $0.05 \%$ Tween 20 (TBST) for $1 \mathrm{~h} 30$ at room temperature. Then, the membranes were incubated with a 1:500 dilution ratio of anti-5mC antibody (Abcam, \#ab73938) and 5\% powdered milk in TBST for $1 \mathrm{~h} 30$, followed by $3 \times 10$ washes with TBST and elliptical agitation. Then incubation with a 1:500 dilution ratio of HRP-conjugated Goat anti-mouse IgG secondary antibody (ClinicSciences, \#AS111772) was done.

The antibody mixture was then removed, and the membrane was washed with TBST under elliptical agitation during $3 \times 10 \mathrm{~min}$. Lecture of the signal was performed using the SuperSignal ${ }^{\mathrm{TM}}$ West Pico Chemiluminescent system (Thermo Fisher Scientific, USA) and the ChemiDoc MP Imaging System. Finally, the densitometry of the $5 \mathrm{mC}$ was analyzed with the software ImageLab5.1. Detailed protocol of this method is found in our preprint [56].

\section{ELISA-based $5 m C$ quantification}

Methylated DNA Quantification Kit (Colorimetric) (Abcam, ab117128) was used to determine global $5 \mathrm{mC}$ level in isolated genomic samples of mollusk controls ( $n=15$ for B. glabrata and $n=10$ for $P$. acuta and $C$. gigas) and Flv1 treated ( $n=15$ for B. glabrata and $n=10$ for $P$. acuta and C. gigas) according to manufacturer instructions. To quantify the absolute amount of methylated DNA, a standard curve was generated plotting the OD values versus the amount of positive control at each concentration point.

\section{Statistical analyses}

The data of mean spot densitometry provided by the software ImageLab5.1 was normalized by the DNA amount (ng) to obtain a relative measure of the $5 \mathrm{mC}$ level. Then, we calculated the $5 \mathrm{mC} \%$ using the following equation:

$$
\begin{aligned}
5 \mathrm{mC} \%= & {[\text { sample densitometry } / \mathrm{ng}] / } \\
& {[\text { positive control densitometry } / \mathrm{ng}] } \\
& \times \text { Positive control } 5 \mathrm{mC} \%
\end{aligned}
$$

where the positive control densitometry corresponds to $6.9 \pm 1.2$ per ng of HeLa cells [20].

Rstudio was used for statistical analysis. Since the data displayed non-normal distribution demonstrated by the Shapiro-Wilk test $(p<0.01)$, Kruskal-Wallis test was used to compare means between groups, then Dunn's multiple comparisons test was applied to test significance of differences in means between the control group and the different treatments. The survival curves were compared by a Mantel-Cox test and the fecundity was measured as the number of offspring and the number of eggs laid by the snails. A contingency table was elaborated with the number of offspring, the non-hatched eggs and the total of eggs laid, then a Fisher's exact test was done to test for significant differences between the treatments. Differences of the morphometric traits between treatments were examined by One-way ANOVA when data were normally distributed (Shapiro-Wilk test was used to verify this assumption) and have a common variance (Levene's test was used to verify equal variances), Welch's ANOVA was applied when the assumption of equal variances was violated, and Kruskal-Wallis test was used when ANOVA assumptions were not met. Pairwise comparisons were done using Tukey multiple pairwise-comparisons, pairwise $t$ test and Wilcoxon rank sum test with continuity correction, respectively.

\section{Library preparation and high throughput reduced representation bisulfite sequencing by epiGBS}

We used an existing protocol called epiGBS [30, 82], a reduced representation bisulfite-sequencing method for cost-effective exploration of DNA methylation and genetic variation designed for multiplexed highthroughput sequencing to maximize sample size while losing loci. epiGBS sequencing was performed with the snails exposed to the DNMTi that showed the most significant changes in the global $5 \mathrm{mC} \%$. Eight samples per treatment were sequenced from control group, Flv1treated, and from the progeny of control and the Flv1treated group. $32 \mathrm{DNA}$ isolated samples were quantified with Qubit fluorometer with the dsDNA HS Assay Kit (Invitrogen). The concentration was homogenized in all samples to $10 \mathrm{ng} / \mu \mathrm{L}$ in a total volume of $35 \mu \mathrm{L}$. epiGBS library preparation was applied as described in the stepby-step most recent protocol [30]. Paired-end sequencing 
( $2 \times 150$ bp) using an Illumina NextSeq ${ }^{\mathrm{TM}} 550$ instrument at the Bio-Environment NGS Platform at the University of Perpignan.

\section{Bioinformatics epiGBS pipeline}

We used the epiGBS2 pipeline (https://github.com/ nioo-knaw/epiGBS2) to remove PCR duplicates and demultiplex samples. We took the filtered and demultiplexed reads from epiGBS2 pipeline to use the pipeline described in [60]. Adapter removing was done using TrimGalore! V06.5 [50], 30 nucleotides were removed from $3^{\prime}$ and $5^{\prime}$ end. Single-end reads were aligned to $B$. glabrata genome $\mathrm{v}$ BglaB1 from https://www.vecto rbase.org/organisms/biomphalaria-glabrata without scaffolds $<5 \mathrm{~kb}$ with BSMAP Mapper [86]. Then single mapped reads were merged and used as input in BSMAP Methylation Caller to get a tabular file with cytosine and thymine counts that was used as input to calculate coverage and Frequency of $\mathrm{C}$ and $\mathrm{T}$ for subsequent analysis.

After alignment, we filtered the CPG sites covered by 8 or more reads and pairwise comparisons and differential methylated analyses were done between control and treated samples in individuals of the same generation (F0 and F1) using MethylKit [2]. The parameters to calculate the Differentially Methylated Cytosines (DMCs) in MethylKit were $q$ value $<0.05$ and $>15 \%$ methylation difference as described in Johnson and Kelly [45] and other less strict parameters adapted to identification of DMCs with weak methylation effect and to small sample sizes, $q$ value $=1$ and $4 \%$ of methylation differences as described in [80]. The visualization of DMCs was done in Integrative Genomics Viewer (IGV). Reference transcriptome of B. glabrata was uploaded with bigwig files to see the location of DMCs. Genomic feature annotation was done by visualizing each differential methylated DMCs. Promoter was arbitrarily defined as the region $2 \mathrm{~Kb}$ upstream of transcription start site (TSS). WGBS raw data were analyzed with the same pipeline for direct comparison with epiGBs libraries. CpG sites with $8 \mathrm{X}$ coverage were used to created bigwig profiles for visualization in IGV (data available at: https://zenodo.org/record/4277533). CpG sites within gene bodies covered by epiGBS and WGBS were extracted by customized R scripts and used to construct histograms and quantiles distribution.

\section{Bisulfite conversion}

$300 \mathrm{ng}$ of DNA from 8 control snails and 8 Flv1-treated snails were bisulfite converted as described previously [10, 28, 38]. $2 \mu \mathrm{g}$ of tRNA from baker's yeast ( $S$. cerevisiae) was added to each sample, $3 \mathrm{M} \mathrm{NaOH}$ was added to a final concentration of $0.3 \mathrm{M}$, and DNA was denatured at $42{ }^{\circ} \mathrm{C}$ for $20 \mathrm{~min}$. Then, $240 \mu \mathrm{L}$ of freshly prepared bisulfite solution (5.41 g of sodium metabisulfite $+7 \mathrm{~mL}$ of distilled water $+0.5 \mathrm{~mL}$ of diluted Hydroquinone $[0.022 \mathrm{~g} / 10 \mathrm{~mL}]$ was added to the denatured DNA samples and incubated in the dark during $4 \mathrm{~h}$ at $55{ }^{\circ} \mathrm{C}$. After that, $200 \mu \mathrm{L}$ of distilled water was added to the samples, and the total volume was transferred to an Amicon column (UFC501024, Millipore, and centrifugation was done at $12,000 \mathrm{~g}$ during $5 \mathrm{~min}$. The column was washed 3 times with $350 \mu \mathrm{L}$ of distilled water and centrifugation at 12,000 $g$ during 5 min was done each time. Following this, $350 \mu \mathrm{L}$ of $0.1 \mathrm{M} \mathrm{NaOH}$ was added to the DNA in the Amicon column, centrifuged at 12,000 $g$ during $5 \mathrm{~min}$; subsequently, $350 \mu \mathrm{L}$ of distilled water was added and a centrifugation at $12,000 \mathrm{~g}$ for $5 \mathrm{~min}$ was done. $50 \mu \mathrm{L}$ of $10 \mathrm{mM}$ TRIS/ $\mathrm{Cl} \mathrm{pH}$ 7.5-8.0 was added to the DNA in the Amicon column and it has been incubated at room temperature during $5 \mathrm{~min}$. Finally, the DNA was collected by centrifugation at $1000 \mathrm{~g}$ for $3 \mathrm{~min}$. DNA was stocked at $-80^{\circ} \mathrm{C}$.

\section{Nested PCR amplification of bisulfite-converted DNA}

Primers were designed for PCR amplification in a CpGrich region of the first intron of the BGLTMP010125 gene using MethPrimer [53]. The external primers (forward ATTGTGTTTTTATTTTGATGGTTATGATA and reverse CCCCAAAACTTACAAAAACCTTAC) were used to amplify a region spanning $861 \mathrm{bp}$ in the BGLTMP010125 gene (Scaffold 4692: 13866-14343). The internal primers used in the nested PCR were the forward primer AGTTTTTTTTATTTTGTATGT AGAGT and the reverse primer ATCCTTTCAAAA AACAAATCATATATC; that amplify an amplicon of $565 \mathrm{bp}$. The initial PCR amplification was performed using $1 \mu \mathrm{L}$ of the bisulfite-converted gDNA samples as templates with external primer set as follows: $94{ }^{\circ} \mathrm{C}$ for $2 \mathrm{~min}, 5$ cycles of $94{ }^{\circ} \mathrm{C}$ for $1 \mathrm{~min}, 50{ }^{\circ} \mathrm{C}$ for $2 \mathrm{~min}$ and $72{ }^{\circ} \mathrm{C}$ for $3 \mathrm{~min}$, followed by 30 cycles of $94{ }^{\circ} \mathrm{C}$ for 30 s, $50{ }^{\circ} \mathrm{C}$ for $2 \mathrm{~min}$ and $72{ }^{\circ} \mathrm{C}$ for $1: 30 \mathrm{~min}$ and finally $72{ }^{\circ} \mathrm{C}$ for $10 \mathrm{~min}$. The nested PCR was performed on a tenfold dilution of the first PCR product using the internal primer set in the same conditions as for the first PCR. PCR products were separated by electrophoresis through $2 \%$ agarose gels to check for the specific amplification of each target gene. PCR products were sequenced by Sanger sequencing (Genoscreen, Lille, France). Sequence chromatograms were analyses as previously described [43] to measure T-peaks heights for unmethylated cytosines converted to thymines, and C-peaks heights for methylated cytosines, providing an estimate for the degree of methylation. 
Table 5 Biomphalaria glabrata gene-specific primers used to amplify gene fragments used in the RT-qPCR

\begin{tabular}{llcc}
\hline Gene & Primer Sequence & Amplicon length & $\begin{array}{c}\text { Primer } \\
\text { efficiency }\end{array}$ \\
\hline 28S ribosomal protein & F: GCTGGCACGACCGCTCCTTT & $100 \mathrm{bp}$ & 2.01 \\
R:TTTGAACCTCGCGACCCGGC & & 2.04 \\
BGLTMP010125-RA: & R: GGACATCTGCCGCCGTAACCT & $112 \mathrm{bp}$ & \\
& F:TTGCTGTGACTGTCAGTGTC & $95 \mathrm{bp}$ & 1.90 \\
\hline
\end{tabular}

\section{Dual DNA and RNA extraction and RT-qPCR}

DNA and RNA were extracted from the same samples $(\mathrm{n}=8$ per treatment) with TRIzol reagent (Sigma Life Science) according to manufacturer's instructions. DNA was subsequently bisulfite converted as described previously and RNA was reverse transcribed to first-strand cDNA using Maxima H Minus First-Strand cDNA Synthesis Kit with dsDNase to remove contaminating genomic DNA and following manufacturer's instructions (Cat. Num. K1682, ThermoFisher, Scientific). Real-time RT-qPCR analyses were performed using the LightCycler 480 System (Roche) in a $10 \mu \mathrm{L}$ final volume comprising $5 \mu \mathrm{L}$ of No Rox SYBR Master Mix blue dTTP (Takyon), $1.75 \mu \mathrm{L}$ of ultrapure Milli-Q water, and $1 \mu \mathrm{L}$ of each primer at a concentration of $1 \mu \mathrm{M}$. The primers used for the RTqPCR are shown in Table 5. Two housekeeping genes were used to normalize the results, the $28 \mathrm{~S}$ ribosomal protein gene and the $\alpha$ Tubulin protein gene, the primers efficiencies were previously evaluated by amplifying four different dilutions of each couple of primers at the RT reaction (1:1, 1:10; 1:100 and 1:1000), a standard curve was generated and the efficiency was calculated with the equation (Efficiency of the amplification $=10^{\wedge(1 /- \text { slope })}$, as earlier described [46]. The cycling program was: denaturation step at $95^{\circ} \mathrm{C}$ for $2 \mathrm{~min}, 40$ cycles of amplification (denaturation at $95{ }^{\circ} \mathrm{C}$ for $10 \mathrm{~s}$, annealing at $58^{\circ} \mathrm{C}$ for 20 $\mathrm{s}$, and elongation at $72{ }^{\circ} \mathrm{C}$ for $30 \mathrm{~s}$ ), with a final elongation step at $72{ }^{\circ} \mathrm{C}$ for $5 \mathrm{~min}$. For each reaction, the cycle threshold $(\mathrm{Ct})$ was determined using the second derivative method of the LightCycler 480 Software release 1.5.0 (Roche). Reactions without RT served as negative control for each sample (in duplicate) to exclude amplification of DNA. None of these negative RT reactions amplified the target. All PCR experiments were performed in duplicates (technical replicates). The mean $\mathrm{Ct}$ value of each reaction was calculated and the $2^{-\Delta \Delta C T}$ method was applied to calculate relative gene expression, the geometric mean of the $\mathrm{Ct}$ values of two housekeeping genes (28S and $\alpha$-Tubulin) were used to normalize gene expression. Corrected melting curves were checked using the Tm-calling method of the LightCycler 480 Software release 1.5.0.

\section{Abbreviations}

6-FAM: 6-Carboxyfluorescein; THUMP: THioUridine synthases, RNA Methyltransferases and Pseudo-uridine synthases; AdoMet: S-Adenosyl-L-methionine; 5mC: 5-Methylcytosine; DNMTs: DNA methyltransferases; DNMTi: DNA methyltransferase inhibitors; 5-AzaC: 5-Azacytidine; BgBRE: Biomphalaria glabrata Strain Brazil BRE; Bge: Biomphalaria glabrata Embryonic.

\section{Supplementary Information}

The online version contains supplementary material available at https://doi. org/10.1186/s13072-021-00422-7.

Additional file 1. Figure S1. Structure, molecular weight (Mw) and molecular. Table S1. Mapping efficiencies of paired-end reads, total number of $\mathrm{CpG}$ sites, $\mathrm{CpG}$ covered by at least 8 reads, number of CpG sites methylated, percentage of CG methylated and sequencing depth of each sample. Formula ofDNMT inhibitors. Table S2. Differential Methylated Cytosines (DMCs) of the F0 generation of snails treated with Flv1. Table S3. Differential Methylated Cytosines (DMCs) of the F1 generation, offspring of the snails treated with Flv1. Table S4. Differential Methylated Cytosines (DMCs) of the F0 generation of snails treated with Flv1 ( $q$ value $=1$, difference cutoff $=4 \%$ ). Table S5. Differential Methylated Cytosines (DMCs) of the F1 generation, offspring of the snails treated with Flv1 ( $q$ value $=1$, difference cutoff $=4 \%$ ). Table S6. DMCs common in F0 and F1 generation ( $q=.05$, cutoff $=15 \%)$. Table S7. DMCs common in F0 and $\mathrm{F} 1$ generation $(q=1$, cutoff $=4 \%$ ).

\section{Acknowledgements}

We are very grateful to R. Galinier and M. Fallet for their support during the optimization of the protocol to measure DNA methylation and to N. Arancibia for breeding of mollusks. We thank L. Halby for its contribution to the discussion of this manuscript and for synthetized compounds used in the screening of effective DNMTi. We thank J.F. Allienne at the Bio-environment platform (University Perpignan Via Domitia) for support in NGS library preparation and sequencing. We thank B. Petton for the breeding of juvenile oysters used in this study and we thank G. Rico for her help in the analysis of dot blot and ELISA of P. acuta and C. gigas. Many thanks also to S. Díaz for her help in the dot blot experiments.

\section{Authors' contributions}

CG and CC designed the study, analyzed data and wrote the manuscript. NL performed the experimental work, processed and analyzed the data, and wrote the manuscript. ML and PBA synthesized the chemical compounds used in this study, elaborated the chemical stability and in vitro inhibition assays and participated in the writing of the manuscript. SI helped in the elaboration of epiGBS libraries. KV and FG helped in the analysis of epiGBSsequencing reads and participated in the writing of the manuscript. PD 
participated in the experimental design and in the writing of the manuscript. $\mathrm{CrC}$ helped with the bioinformatics analysis.

\section{Funding}

This work was supported by Wellcome Trust strategic award [107475/Z/15/Z] and by a PhD grant to NL from the Region Occitanie (EPIPARA project) and the University of Perpignan Via Domitia graduate school ED305. With the support of LabEx CeMEB, an ANR "Investissements d'avenir" program (ANR10-LABX-04-01) through the Environmental Epigenomics Platform and the "projets de recherche exploratoires du CeMEB 2018" project "Epigenetics of inbreeding depression (EPID)". This study is set within the framework of the "Laboratoires d'Excellences (LABEX)"TULIP (ANR-10-LABX-41).

\section{Availability of data and materials}

All Flv substrates are available on request. Raw data are available at NCBI SRA PRJNA771265.

\section{Declarations}

\section{Ethics approval and consent to participate}

The Direction Départementale de la Cohésion Sociale et de la Protection des Populations (DDSCPP) provided the permit N ${ }^{\circ} \mathrm{C} 66-136-01$ to IHPE for experiments on animals.

\section{Consent for publication}

All the authors read and endorsed the manuscript.

\section{Competing interests}

The authors declare no conflict of interest.

\begin{abstract}
Author details
'IHPE, Univ Perpignan Via Domitia, CNRC, Ifremer, Univ Montpellier, Perpignan, France. ${ }^{2}$ Institut des Biomolécules Max Mousseron (IBMM), UMR 5247, CNRS, Univ Montpellier, ENSCM, Montpellier, France. ${ }^{3}$ Epigenetic Targeting of Cancer (ETaC), CNRS FRE3600, Centre de Recherche et Développement Pierre Fabre, Toulouse, France. ${ }^{4}$ Bioinformatics Unit, Netherlands Institute of Ecology (NIOO-KNAW), Wageningen, The Netherlands. ${ }^{5}$ Epigenetic Chemical Biology (EpiChBio), Department Structural Biology and Chemistry, UMR 3523, CNRS, Institute Pasteur, 75015 Paris, France. ${ }^{6}$ Department of Terrestrial Ecology, Netherlands Institute of Ecology (NIOO-KNAW), Wageningen, The Netherlands. ${ }^{7}$ Centre d'Ecologie Fonctionnelle et Evolutive (CEFE), Univ. Montpellier, CNRS Université Paul Valéry Montpellier - EPHE, 1919 Route de Mende, 34293 Montpellier Cedex 5, France.
\end{abstract}

Received: 16 July 2021 Accepted: 1 October 2021

Published online: 26 October 2021

\section{References}

1. Adema CM, Hillier LW, Jones CS, Loker ES, Knight M, Minx P, Oliveira G, Raghavan N, Shedlock A, L. R. do Amaral, H. D. Arican-Goktas, J. G. Assis, E. H. Baba, O. L. Baron, C. J. Bayne, U. Bickham-Wright, K. K. Biggar, M. Blouin, B. C. Bonning, C. Botka, J. M. Bridger, K. M. Buckley, S. K. Buddenborg, R. Lima Caldeira, J. Carleton, O. S. Carvalho, M. G. Castillo, I. W. Chalmers, M. Christensens, S. Clifton, C. Cosseau, C. Coustau, R. M. Cripps, Y. CuestaAstroz, S. F. Cummins, L. di Stephano, N. Dinguirard, D. Duval, S. Emrich, C. Feschotte, R. Feyereisen, P. FitzGerald, C. Fronick, L. Fulton, R. Galinier, S. G. Gava, M. Geusz, K. K. Geyer, G. I. Giraldo-Calderón, M. de Souza Gomes, M. A. Gordy, B. Gourbal, C. Grunau, P. C. Hanington, K. F. Hoffmann, D. Hughes, J. Humphries, D. J. Jackson, L. K. Jannotti-Passos, W. de Jesus Jeremias, S. Jobling, B. Kamel, A. Kapusta, S. Kaur, J. M. Koene, A. B. Kohn, D. Lawson, S. P. Lawton, D. Liang, Y. Limpanont, S. Liu, A. E. Lockyer, T. L. Lovato, F. Ludolf, V. Magrini, D. P. McManus, M. Medina, M. Misra, G. Mitta, G. M. Mkoji, M. J. Montague, C. Montelongo, L. L. Moroz, M. C. Munoz-Torres, U. Niazi, L. R. Noble, F. S. Oliveira, F. S. Pais, A. T. Papenfuss, R. Peace, J. J. Pena, E. A. Pila, T. Quelais, B. J. Raney, J. P. Rast, D. Rollinson, I. C. Rosse, B. Rotgans, E. J. Routledge, K. M. Ryan, L. L. S. Scholte, K. B. Storey, M. Swain, J. A. Tennessen, C. Tomlinson, D. L. Trujillo, E. V. Volpi, A. J. Walker, T. Wang, I. Wannaporn, W. C. Warren, X. J. Wu, T. P. Yoshino, M. Yusuf, S. M. Zhang,
M. Zhao, and R. K. Wilson. Whole genome analysis of a schistosomiasistransmitting freshwater snail. Nat Commun. 2017;8:15451. https://doi. org/10.1038/ncomms15451.

2. Akalin A, Kormaksson M, Li S, Garrett-Bakelman FE, Figueroa ME, Melnick A, Mason CE. methylKit: a comprehensive R package for the analysis of genome-wide DNA methylation profiles. Genome Biol. 2012;13(10):R87. https://doi.org/10.1186/gb-2012-13-10-r87.

3. Aliaga B, Bulla I, Mouahid G, Duval D, Grunau C. Universality of the DNA methylation codes in Eucaryotes. Sci Rep. 2019;9(1):173. https://doi.org/ 10.1038/s41598-018-37407-8.

4. Allan ERO, Bollmann S, Peremyslova E, Blouin M. Neither heat pulse, nor multigenerational exposure to a modest increase in water temperature, alters the susceptibility of Guadeloupean. PeerJ. 2020;8: e9059. https:// doi.org/10.7717/peerj.9059.

5. Athanasio CG, Sommer U, Viant MR, Chipman JK, Mirbahai L. Use of 5-azacytidine in a proof-of-concept study to evaluate the impact of prenatal and post-natal exposures, as well as within generation persistent DNA methylation changes in Daphnia. Ecotoxicology. 2018;27(5):556-68. https://doi.org/10.1007/s10646-018-1927-3.

6. Baccarelli A, Bollati V. Epigenetics and environmental chemicals. Curr Opin Pediatr. 2009;21(2):243-51.

7. Bal N, Kumar A, Nugegoda D. Assessing multigenerational effects of prednisolone to the freshwater snail, Physa acuta (Gastropoda: Physidae). J Hazard Mater. 2017;339:281-91. https://doi.org/10.1016/j.jhazmat.2017. 06.024 .

8. Baubec T, Pecinka A, Rozhon W, Mittelsten Scheid O. Effective, homogeneous and transient interference with cytosine methylation in plant genomic DNA by zebularine. Plant J. 2009;57(3):542-54. https://doi.org/ 10.1111/j.1365-313X.2008.03699.x.

9. Bossdorf O, Richards CL, Pigliucci M. Epigenetics for ecologists. Ecol Lett. 2008;11(2):106-15. https://doi.org/10.1111/j.1461-0248.2007.01130.x.

10. Boyd VL, Zon G. Bisulfite conversion of genomic DNA for methylation analysis: protocol simplification with higher recovery applicable to limited samples and increased throughput. Anal Biochem. 2004;326(2):27880. https://doi.org/10.1016/j.ab.2003.11.020.

11. Capuano F, Mülleder M, Kok R, Blom HJ, Ralser M. Cytosine DNA methylation is found in Drosophila melanogaster but absent in Saccharomyces cerevisiae, Schizosaccharomyces pombe, and other yeast species. Anal Chem. 2014;86(8):3697-702. https://doi.org/10.1021/ac500447w.

12. Carvalho S, Caldeira RL, Simpson AJ, Vidigal TH. Genetic variability and molecular identification of Brazilian Biomphalaria species (Mollusca: Planorbidae). Parasitology. 2001;123(Suppl):S197-209. https://doi.org/10. 1017/s0031182001008058.

13. Ceccaldi A, Rajavelu A, Champion C, Rampon C, Jurkowska R, Jankevicius G, Senamaud-Beaufort C, Ponger L, Gagey N, Ali HD, Tost J, Vriz S, Ros S, Dauzonne D, Jeltsch A, Guianvarc'h D, Arimondo PB. C5-DNA methyltransferase inhibitors: from screening to effects on zebrafish embryo development. ChemBioChem. 2011;12(9):1337-45. https://doi.org/10. 1002/cbic.201100130

14. Champion C, Guianvarc'h D, Sénamaud-Beaufort C, Jurkowska RZ, Jeltsch A, Ponger L, Guieysse-Peugeot AL. Mechanistic insights on the inhibition of c5 DNA methyltransferases by zebularine. PLoS ONE. 2010;5(8): e12388. https://doi.org/10.1371/journal.pone.0012388.

15. Chen T. Mechanistic and functional links between histone methylation and DNA methylation. Prog Mol Biol Transl Sci. 2011;101:335-48. https:// doi.org/10.1016/B978-0-12-387685-0.00010-X.

16. Cheng JC, Weisenberger DJ, Gonzales FA, Liang G, Xu GL, Hu YG, Marquez VE, Jones PA. Continuous zebularine treatment effectively sustains demethylation in human bladder cancer cells. Mol Cell Biol. 2004;24(3):1270-8.

17. Cosseau C, Wolkenhauer O, Padalino G, Geyer KK, Hoffmann KF, Grunau C. (Epi)genetic Inheritance in Schistosoma mansoni: A Systems Approach. Trends Parasitol. 2017;33(4):285-94. https://doi.org/10.1016/j.pt.2016.12. 002.

18. Cosseau C, Azzi A, Rognon A, Boissier J, Gourbiere S, Roger E, Mitta G, Grunau C. Epigenetic and phenotypic variability in populations of Schistosoma mansoni-a possible kick-off for adaptive host/parasite evolution. Oikos. 2010;119(4):669-78.

19. de Lorgeril J, Lucasson A, Petton B, Toulza E, Montagnani C, Clerissi C, Vidal-Dupiol J, Chaparro C, Galinier R, J.-Michel Escoubas, P. Haffner, L. Dégremont, G. M. Charrière, M. Lafont, A. Delort, A. Vergnes, M. Chiarello, 
N. Faury, T. Rubio, M. A. Leroy, A. Pérignon, D. Régler, B. Morga, M. AlunnoBruscia, P. Boudry, F. Le Roux, D. Destoumieux-Garzón, Y. Gueguen, and G. Mitta. Immune-suppression by OsHV-1 viral infection causes fatal bacteraemia in Pacific oysters. Nat Commun. 2018;9(1):4215. https://doi. org/10.1038/s41467-018-06659-3.

20. Diala ES, Hoffman RM. Hypomethylation of HeLa cell DNA and the absence of 5-methylcytosine in SV40 and adenovirus (type 2) DNA: analysis by HPLC. Biochem Biophys Res Commun. 1982;107(1):19-26.

21. Dreyfuss $G$, Vignoles $P$, Abrous M, Rondelaud D. Unusual snail species involved in the transmission of Fasciola hepatica in watercress beds in central France. Parasite. 2002;9(2):113-20. https://doi.org/10.1051/paras ite/2002092113.

22. Dupont C, Armant DR, Brenner CA. Epigenetics: definition, mechanisms and clinical perspective. Semin Reprod Med. 2009;27(5):351-7. https:// doi.org/10.1055/s-0029-1237423.

23. Erdmann A, Halby L, Fahy J, Arimondo PB. Targeting DNA Methylation with Small Molecules: What's Next? J Med Chem. 2015;58(6):2569-83. https://doi.org/10.1021/jm500843d.

24. Fallet M, Luquet E, David P, Cosseau C. Epigenetic inheritance and intergenerational effects in mollusks. Gene. 2020;729: 144166. https:// doi.org/10.1016/j.gene.2019.144166.

25. Feng S, Cokus SJ, Zhang X, Chen PY, Bostick M, Goll MG, Hetzel J, Jain J, Strauss SH, Halpern ME, Ukomadu C, Sadler KC, Pradhan S, Pellegrini M, Jacobsen SE. Conservation and divergence of methylation patterning in plants and animals. Proc Natl Acad Sci U S A. 2010;107(19):8689-94. https://doi.org/10.1073/pnas.1002720107.

26. Flotho C, Claus R, Batz C, Schneider M, Sandrock I, Ihde S, Plass C, Niemeyer CM, Lübbert M. The DNA methyltransferase inhibitors azacitidine, decitabine and zebularine exert differential effects on cancer gene expression in acute myeloid leukemia cells. Leukemia. 2009:23(6):1019-28. https://doi.org/10.1038/leu.2008.397.

27. Fneich S, Dheilly N, Adema C, Rognon A, Reichelt M, Bulla J, Grunau C, Cosseau C. 5-methyl-cytosine and 5-hydroxy-methyl-cytosine in the genome of Biomphalaria glabrata, a snail intermediate host of Schistosoma mansoni. Parasit Vectors. 2013;6(1):167.

28. Frommer M, McDonald LE, Millar DS, Collis CM, Watt F, Grigg GW, Molloy PL, Paul $\mathrm{CL}$. A genomic sequencing protocol that yields a positive display of 5-methylcytosine residues in individual DNA strands. Proc Natl Acad Sci U S A. 1992;89(5):1827-31.

29. Ganesan A, Arimondo PB, Rots MG, Jeronimo C, Berdasco M. The timeline of epigenetic drug discovery: from reality to dreams. Clin Epigenetics. 2019;11(1):174

30. Gawehns F, Postuma M, van Gurp TP, Wagemaker CAM, Fatma S, Van Antro M, Mateman C, Milanovic-Ivanovic S, van Oers K, Große I. epiGBS2: an improved protocol and automated snakemake workflow for highly multiplexed reduced representation bisulfite sequencing. bioRxiv. 2020

31. Geyer KK, Munshi SE, Vickers M, Squance M, Wilkinson TJ, Berrar D, Chaparro C, Swain MT, Hoffmann KF. The anti-fecundity effect of 5-azacytidine (5-AzaC) on Schistosoma mansoni is linked to dis-regulated transcription, translation and stem cell activities. Int J Parasitol Drugs Drug Resist. 2018;8(2):213-22. https://doi.org/10.1016/j.ijpddr.2018.03. 006.

32. Geyer KK, Niazi UH, Duval D, Cosseau C, Tomlinson C, Chalmers IW, Swain MT, Cutress DJ, Bickham-Wright U, Munshi SE, Grunau C, Yoshino TP, Hoffmann KF. The Biomphalaria glabrata DNA methylation machinery displays spatial tissue expression, is differentially active in distinct snail populations and is modulated by interactions with Schistosoma mansoni. PLoS Negl Trop Dis. 2017;11(5): e0005246. https://doi.org/10.1371/journal.pntd. 0005246.

33. Geyer KK, Rodríguez López CM, Chalmers IW, Munshi SE, Truscott M, Heald J, Wilkinson MJ, Hoffmann KF. Cytosine methylation regulates oviposition in the pathogenic blood fluke Schistosoma mansoni. Nat Commun. 2011;2:424. https://doi.org/10.1038/ncomms1433.

34. Glastad KM, Hunt BG, Yi SV, Goodisman MA. DNA methylation in insects: on the brink of the epigenomic era. Insect Mol Biol. 2011;20(5):553-65. https://doi.org/10.1111/j.1365-2583.2011.01092.x.

35. Gnyszka A, Jastrzebski Z, Flis S. DNA methyltransferase inhibitors and their emerging role in epigenetic therapy of cancer. Anticancer Res. 2013;33(8):2989-96.
36. Gowher H, Leismann O, Jeltsch A. DNA of Drosophila melanogaster contains 5-methylcytosine. EMBO J. 2000;19(24):6918-23. https://doi.org/ 10.1093/emboj/19.24.6918.

37. Gros C, Fahy J, Halby L, Dufau I, Erdmann A, Gregoire JM, Ausseil F, Vispé $\mathrm{S}$, Arimondo PB. DNA methylation inhibitors in cancer: recent and future approaches. Biochimie. 2012;94(11):2280-96. https://doi.org/10.1016/j. biochi.2012.07.025.

38. Grunau C, Clark SJ, Rosenthal A. Bisulfite genomic sequencing: systematic investigation of critical experimental parameters. Nucleic Acids Res. 2001;29(13):E65-75. https://doi.org/10.1093/nar/29.13.e65.

39. Halby L, Menon Y, Rilova E, Pechalrieu D, Masson V, Faux C, Bouhlel MA, David-Cordonnier MH, Novosad N, Aussagues Y, Samson A, Lacroix L, Ausseil F, Fleury L, Guianvarc'h D, Ferroud C, Arimondo PB. Rational Design of Bisubstrate-Type Analogues as Inhibitors of DNA Methyltransferases in Cancer Cells. J Med Chem. 2017;60(11):4665-79. https://doi.org/10.1021/ acs.jmedchem.7b00176.

40. Hendrich B, Tweedie S. The methyl-CpG binding domain and the evolving role of DNA methylation in animals. Trends Genet. 2003;19(5):269-77. https://doi.org/10.1016/S0168-9525(03)00080-5.

41. Jablonka E, Lamb MJ. Epigenetic inheritance in evolution. J Evol Biol. 1998;11(2):159-83. https://doi.org/10.1046/j.1420-9101.1998.11020159.x.

42. Jablonka E, Lamb MJ. Epigenetic inheritance and evolution: the Lamarckian dimension. Oxford: Oxford University Press on Demand; 1999.

43. Jiang M, Zhang Y, Fei J, Chang X, Fan W, Qian X, Zhang T, Lu D. Rapid quantification of DNA methylation by measuring relative peak heights in direct bisulfite-PCR sequencing traces. Lab Invest. 2010;90(2):282-90. https://doi.org/10.1038/labinvest.2009.132.

44. Johannes F, Porcher E, Teixeira FK, Saliba-Colombani V, Simon M, Agier N, Bulski A, Albuisson J, Heredia F, Audigier P, Bouchez D, Dillmann C, Guerche P, Hospital F, Colot V. Assessing the impact of transgenerational epigenetic variation on complex traits. PLoS Genet. 2009:5(6): e1000530. https://doi.org/10.1371/journal.pgen.1000530.

45. Johnson KM, Kelly MW. Population epigenetic divergence exceeds genetic divergence in the Eastern oyster Crassostrea virginica in the Northern Gulf of Mexico. Evol Appl. 2020;13(5):945-59.

46. Jozefczuk J, James A. Quantitative real-time PCR-based analysis of gene expression. In: Methods in enzymology. Elsevier; 2011. p. 99-109.

47. Kanev I. Life-cycle, delimitation and redescription of Echinostoma revolutum (Froelich, 1802)(Trematoda: Echinostomatidae). Syst Parasitol. 1994;28(2):125-44.

48. Keller TE, Han P, Yi SV. Evolutionary Transition of Promoter and Gene Body DNA Methylation across Invertebrate-Vertebrate Boundary. Mol Biol Evol. 2016;33(4):1019-28. https://doi.org/10.1093/molbev/msv345.

49. Knight M, Ittiprasert W, Arican-Goktas HD, Bridger JM. Epigenetic modulation, stress and plasticity in susceptibility of the snail host Biomphalaria glabrata, to Schistosoma mansoni infection. Int J Parasitol. 2016;46(7):389-94. https://doi.org/10.1016/j.jpara.2016.03.003.

50. Krueger F. Trim Galore: a wrapper tool around Cutadapt and FastQC to consistently apply quality and adapter trimming to FastQ files, with some extra functionality for Mspl-digested RRBS-type (Reduced Representation Bisufite-Seq) libraries. 2012. http://www.bioinformatics.babraham.ac.uk/ projects/trim_galore/. Accessed 28 Apr 2016.

51. Lee TF, Zhai J, Meyers BC. «Conservation and divergence in eukaryotic DNA methylation". Proc Natl Acad Sci. 2010;107(20):9027-8.

52. Li E, Zhang Y. DNA methylation in mammals. Cold Spring Harb Perspect Biol. 2014;6(5): a019133. https://doi.org/10.1101/cshperspect.a019133.

53. Li LC, Dahiya R. MethPrimer: designing primers for methylation PCRs. Bioinformatics. 2002;18(11):1427-31. https://doi.org/10.1093/bioinforma tics/18.11.1427.

54. Lopez M, Halby L, Arimondo PB. DNA Methyltransferase Inhibitors: Development and Applications. Adv Exp Med Biol. 2016;945:431-73. https:// doi.org/10.1007/978-3-319-43624-1_16.

55. Luchtel D. Gonadal development and sex determination in pulmonate molluscs. I. Arion circumscriptus. Z Zellforsch Mikrosk Anat. 1972;130(3):279-301. https://doi.org/10.1007/bf00306943.

56. Luviano N, Diaz-Palma S, Cosseau C, Grunau C. A simple Dot Blot Assay for population scale screening of DNA methylation. Biorxiv. 2018. https:// doi.org/10.1101/454439.

57. Maharajan P, Maharajan V, Branno M, Scarano E. Effects of 5 azacytidine on DNA methylation and early development of sea urchins and ascidia. Differentiation. 1986;32(3):200-7. 
58. McManus DP. Defeating Schistosomiasis. N Engl J Med. 2019;381 (26):2567-8. https://doi.org/10.1056/NEJMe1913771.

59. Meng H, Cao Y, Qin J, Song X, Zhang Q, Shi Y, Cao L. DNA methylation, its mediators and genome integrity. Int J Biol Sci. 2015;11(5):604-17. https:// doi.org/10.7150/ijbs.11218.

60. Meröndun J, Murray DL, Shafer ABA. Genome-scale sampling suggests cryptic epigenetic structuring and insular divergence in Canada lynx. Mol Ecol. 2019;28(13):3186-96. https://doi.org/10.1111/mec.15131.

61. Moore LD, Le T, Fan G. DNA methylation and its basic function. Neuropsychopharmacology. 2013;38(1):23-38. https://doi.org/10.1038/npp.2012. 112.

62. Müller R, Charaf S, Scherer C, Oppold A, Oehlmann J, Wagner M. Phenotypic and epigenetic effects of vinclozolin in the gastropod Physella acuta. J Molluscan Studies. 2016;82(2):320-7. https://doi.org/10.1093/ mollus/eyv069.

63. Nicoglou A, Merlin F. Epigenetics: A way to bridge the gap between biological fields. Stud Hist Philos Biol Biomed Sci. 2017;66:73-82. https:// doi.org/10.1016/j.shpsc.2017.10.002.

64. Pechalrieu D, Etievant C, Arimondo PB. DNA methyltransferase inhibitors in cancer: From pharmacology to translational studies. Biochem Pharmacol. 2017;129:1-13. https://doi.org/10.1016/j.bcp.2016.12.004.

65. Pechalrieu D, Dauzonne D, Arimondo PB, Lopez M. Synthesis of novel 3-halo-3-nitroflavanones and their activities as DNA methyltransferase inhibitors in cancer cells. Eur J Med Chem. 2020;186: 111829. https://doi. org/10.1016/j.ejmech.2019.111829.

66. Prokopuk L, Hogg K, Western PS. Pharmacological inhibition of EZH2 disrupts the female germline epigenome. Clin Epigenetics. 2018;10:33. https://doi.org/10.1186/s13148-018-0465-4.

67. Reamon-Buettner SM, Mutschler V, Borlak J. The next innovation cycle in toxicogenomics: environmental epigenetics. Mutat Res. 2008;659(12):158-65. https://doi.org/10.1016/j.mrrev.2008.01.003.

68. Rivière $\mathrm{G}$. Epigenetic features in the oyster Crassostrea gigas suggestive of functionally relevant promoter DNA methylation in invertebrates. Front Physiol. 2014;5:129.

69. Roberts SB, Gavery MR. Is There a Relationship between DNA Methylation and Phenotypic Plasticity in Invertebrates? Front Physiol. 2012;2:116. https://doi.org/10.3389/fphys.2011.00116.

70. Rondon R, Grunau C, Fallet M, Charlemagne N, Sussarellu R, Chaparro C, Montagnani C, Mitta G, Bachère E, Akcha F, Cosseau C. Effects of a parental exposure to diuron on Pacific oyster spat methylome. Environ Epigenet. 2017;3(1):004. https://doi.org/10.1093/eep/dvx004.

71. Sarda S, Zeng J, Hunt BG, Yi V, Soojin. The evolution of invertebrate gene body methylation. Mol Biol Evol. 2012;29(8):1907-16.

72. Schübeler D. Function and information content of DNA methylation. Nature. 2015;517(7534):321-6. https://doi.org/10.1038/nature14192.

73. Seeland A, Albrand J, OehImann J, Müller R. Life stage-specific effects of the fungicide pyrimethanil and temperature on the snail Physella acuta (Draparnaud, 1805) disclose the pitfalls for the aquatic risk assessment under global climate change. Environ Pollut. 2013;174:1-9.

74. Sullivan J. Reversal of schistosome resistance in Biomphalaria glabrata by heat shock may be dependent on snail genotype. J Parasitol. 2018. https://doi.org/10.1645/17-110.

75. Suzuki MM, Bird A. DNA methylation landscapes: provocative insights from epigenomics. Nat Rev Genet. 2008;9(6):465-76. https://doi.org/10. 1038/nrg2341.

76. Takiguchi M, Achanzar WE, Qu W, Li G, Waalkes MP. Effects of cadmium on DNA-(Cytosine-5) methyltransferase activity and DNA methylation status during cadmium-induced cellular transformation. Exp Cell Res. 2003:286(2):355-65.

77. Tan W, Zhou W, Yu HG, Luo HS, Shen L. The DNA methyltransferase inhibitor zebularine induces mitochondria-mediated apoptosis in gastric cancer cells in vitro and in vivo. Biochem Biophys Res Commun. 2013;430(1):250-5. https://doi.org/10.1016/j.bbrc.2012.10.143.

78. Theron A, Rognon A, Gourbal B, Mitta G. Multi-parasite host susceptibility and multi-host parasite infectivity: a new approach of the Biomphalaria glabrata/Schistosoma mansoni compatibility polymorphism. Infect Genet Evol. 2014;26:80-8. https://doi.org/10.1016/j.meegid.2014.04.025.

79. Thornhill JA, Jones JT, Kusel JR. Increased oviposition and growth in immature Biomphalaria glabrata after exposure to Schistosoma mansoni. Parasitology. 1986;93(Pt 3):443-50.

80. Tran H, Zhu H, Wu X, Kim G, Clarke CR, Larose H, Zhang L. Identification of Differentially Methylated Sites with Weak Methylation Effects. Genes. 2018;9(2):75.

81. Ueno M, Katayama K, Nakayama H, Doi K. Mechanisms of 5-azacytidine $(5 \mathrm{AzC})$-induced toxicity in the rat foetal brain. Int J Exp Pathol. 2002;83(3):139-50. https://doi.org/10.1046/j.1365-2613.2002.00225.x.

82. van Gurp TP, Wagemaker NC, Wouters B, Vergeer P, Ouborg JN, Verhoeven $\mathrm{KJ}$. epiGBS: reference-free reduced representation bisulfite sequencing. Nat Methods. 2016;13(4):322-4. https://doi.org/10.1038/nmeth.3763.

83. Vinarski MV. The history of an invasion: phases of the explosive spread of the physid snail Physella acuta through Europe, Transcaucasia and Central Asia. Biol Invasions. 2017;19(4):1299-314.

84. Weber M, Davies JJ, Wittig D, Oakeley EJ, Haase M, Lam WL, Schuebeler D. Chromosome-wide and promoter-specific analyses identify sites of differential DNA methylation in normal and transformed human cells. Nat Genet. 2005;37(8):853-62.

85. Western PS. Epigenomic drugs and the germline: Collateral damage in the home of heritability? Mol Cell Endocrinol. 2018:468:121-33. https:// doi.org/10.1016/j.mce.2018.02.008.

86. Xi Y, Li W. BSMAP: whole genome bisulfite sequence MAPping program. BMC Bioinformatics. 2009;10:232. https://doi.org/10.1186/ 1471-2105-10-232.

87. Xiang H, Zhu J, Chen Q, Dai F, Li X, Li M, Zhang H, Zhang G, Li D, Dong Y, Zhao L, Lin Y, Cheng D, Yu J, Sun J, Zhou X, Ma K, He Y, Zhao Y, Guo S, Ye M, Guo G, Li Y, Li R, Zhang X, Ma L, Kristiansen K, Guo Q, Jiang J, Beck S, Xia Q, Wang W, Wang J. Single base-resolution methylome of the silkworm reveals a sparse epigenomic map. Nat Biotechnol. 2010;28(5):516-20. https://doi.org/10.1038/nbt.1626.

88. Zemach A, McDaniel IE, Silva P, Zilberman D. Genome-wide evolutionary analysis of eukaryotic DNA methylation. Science. 2010;328(5980):916-9.

89. Zilberman D. The evolving functions of DNA methylation. Curr Opin Plant Biol. 2008;11(5):554-9. https://doi.org/10.1016/j.pbi.2008.07.004.

\section{Publisher's Note}

Springer Nature remains neutral with regard to jurisdictional claims in published maps and institutional affiliations.

Ready to submit your research? Choose BMC and benefit from

- fast, convenient online submission

- thorough peer review by experienced researchers in your field

- rapid publication on acceptance

- support for research data, including large and complex data types

- gold Open Access which fosters wider collaboration and increased citations

- maximum visibility for your research: over 100M website views per year

At BMC, research is always in progress.

Learn more biomedcentral.com/submissions 